\title{
REVIEW
}

\section{Wireless Wearable Electrochemical Sensors: A Review}

Thais Maria Rabelo Alves (iD, Patricia Batista Deroco iD, Dagwin Wachholz Junior iD, Lourenço Henrique Bittar Vidotto iD and Lauro Tatsuo Kubota iD

Instituto de Química, Universidade Estadual de Campinas (Unicamp), Rua Josué de Castro, Cidade Universitária, 13083861, Campinas, SP, Brazil

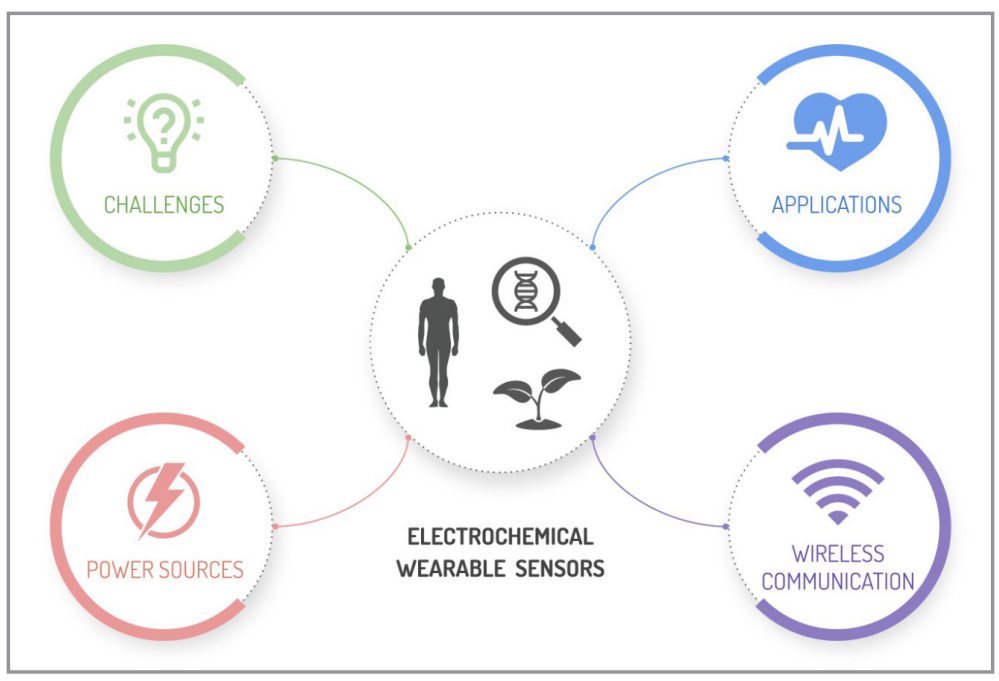
due to its features such as simple structure, the possibility of miniaturization, comfort, simplicity of operation, high sensitivity, fast response, relatively low energy consumption and low manufacturing cost. Furthermore, wearable electrochemical sensors enable obtaining insights into individuals health status through the noninvasive monitoring of clinically relevant biomarkers in different biofluids without complex sampling, manipulation and treatment steps. In this review, we present the main advances in technologies used in the development of fully integrated wireless wearable electrochemical devices, such as communication protocols, data collection and privacy concerns and power sources. We also discuss in a critical way the main challenges, trends, strategies and new technologies that will drive this research line in the future. Lastly, we highlight the progress in the last few years in healthcare, sports, security and defense, and forensic applications.

Keywords: wearable sensors, electroanalysis, flexible electronics, Internet-of-Things, continuous monitoring.

Cite: Alves, T. M. R.; Deroco, P. B.; Wachholz Junior, D.; Vidotto, L. H. B.; Kubota, L. T. Wireless Wearable Electrochemical Sensors: A Review. Braz. J. Anal. Chem., 2021, 8 (31), pp 22-50. doi: http://dx.doi.org/10.30744/brjac.2179-3425.RV-62-2020

Received 23 October 2020, Revised 10 March 2021, Accepted 13 March 2021, Available online 26 March 2021. 


\section{INTRODUCTION}

Interest in the development of wearable sensors has been steadily increased over the last years, following advancements in material science, flexible electronics, microfabrication, miniaturization techniques, and the rapid growth of the Internet-of-Things (IoT), as it becomes easier to integrate features such as realtime data acquisition and wireless communication into such devices. The loT is a new prototype that is being developed in the current wireless telecommunications landscape, and its concept is based on a wide network of connected things, such as sensors, actuators, identifiers, and products, which can interact with others autonomously and also cooperate to achieve a common goal $[1,2]$. The loT is not just an idea, but it is already a technological application from which our life can benefit [3].

In the field of analytical chemistry, these concept of connected wireless communication with chemical (bio)sensors allow analytes to be monitored in situ from a distance, even in hazardous places. Using the right wireless protocol, multiple devices can be linked together in networks, providing real-time data over large areas [4]. Therefore, the choice of a wireless technology depends on the connectivity requirements for its application. The most common technologies recently in use for wireless communication include Bluetooth, ZigBee, radio-frequency identification (RFID), and near-field communication (NFC), each with its own set of features and advantages [5]. Smartphones are also worth mentioning in this context, as they have been increasingly used in chemical sensing, due to its pervasiveness and computational capability. A smartphone can be used to perform data acquisition and analyses in real-time, typically using built-in radio protocols. Furthermore, integrated cameras enable it to also serve as the detector in optical sensor systems [6].

Chemical sensors can be classified according to their transduction element, which can be electrochemical, optical and piezoelectric. In the scope of wearable devices, electrochemical sensors have a great domain in their development due to characteristics such as the possibility of miniaturization, flexibility, comfort, simplicity of operation, compatibility with different materials and most importantly, can operate with inexpensive electronic devices powered by battery instrumentation $[7,8]$.

Currently, there is a great expectation for the development of fully integrated devices, with a bio(sensing) signal processor and powered by battery. These fully integrated devices operate as a "microcomputer" connecting all detection processes, from the collection and processing of information to deliver the results [9]. Wireless communication is essential to ensure complete mobility of wearable electrochemical sensors. Therefore, the combination of these components brings a new class of hybrid devices, the wireless wearable electrochemical sensors [2].

Wireless electrochemical sensors offer real-time monitoring of analytical data not only in hospital settings but also during regular day-to-day activities [10-12]. This represents an opportunity to decrease healthcare costs, improving preventive and personalized medicine approaches [10]. While most these new wearable sensors devices have focused on fitness and healthcare applications, recent efforts appear in the development of on-body sensors for diverse security and defense, environmental and forensic applications. Consequently, several studies have described wearable electrochemical sensors that can monitor, for example, toxic gases [13,14], pesticides [15], illicit and licit drugs [16-18], explosives and heavy metal [19], electrolytes [20], and metabolites [21] on-body via biofluids, such as saliva [22], tears [23], and sweat [24]. This progress has been the subject of several recent review articles [2,25-29].

This growing demand for real time analysis and the continuous monitoring of relevant (bio)molecules has been spurred the development in the field of wearable technology aiming a noninvasive data collection at a low cost. As a result, the wearable market had a historic growth in 2019, which was more than double compared to 2014 [30]. As encouraging as these developments are, the impact of existing wearable electrochemical sensors fully integrated with wireless data transmission technology still remains at an early stage. There are still challenges and limitations to be overcome in order for these devices to be marketed. This review focuses on these challenges and technological gaps in the field of wearable electrochemical sensors. The main topics discussed include the development of available wireless communication protocols, data collection and privacy concerns, power sources for wearable devices, challenges involving 
electrode materials, sampling, sensitivity, stability and applications in healthcare, sports, environmental security and forensic analyses.

\section{WEARABLE ELECTROCHEMICAL SENSORS CHALLENGES Principles of electrochemical sensor}

The great advantages of coupling wireless communication to different types of wearable sensors are the mobility of these class of devices, the possibility of obtaining real-time data acquisition and application in different areas like homeland defense, home-based healthcare, and food logistics [31,32].

Electrochemical sensors are the most used in the wireless chemical sensor field, due to features such as simple structure, possibility of miniaturization, comfort and simplicity of operation, combined with high sensitivity, fast response, low energy consumption and low manufacturing cost [7]. Basically, a wireless electrochemical sensor transduces the electrochemical interaction of an analyte at an electrode into a voltage or current signal, which can be transmitted through a wired or wireless communication module. The electrochemical signal can be amperometric, voltammetric, potentiometric and impedimetric [33].

The predominant transduction methods for the development of wireless electrochemical sensors are potentiometric, which measure the potential difference between an indicator electrode (ion-selective electrode) and a reference electrode; voltammetric, which measure current flow varying potential and amperometric, which measure current at a constant potential.

The potentiometric methods are the most used, due to less complexity in its electrochemical transduction components [2]. The development of wearable potentiometric sensors has been reported for the measurement of various electrolytes present in sweat, including sodium [34], potassium [12], chloride [35], ammonia [36], calcium and hydrogen ions [37]. Although potentiometric sensors operate easily wirelessly and without a battery, their sensing capability is limited to electrolyte levels and therefore are not suitable to detect other physiologically relevant species, such as metabolites, drugs, and proteins [38].

Wearable amperometric devices typically use enzymes to achieve selectivity. The incorporation of enzymes for specific target analytes/metabolites may require the use of high voltages to trigger the enzymatic reaction, which can generate interference signals. To overcome this problem, an electron transfer mediator can be incorporated to decrease the redox potential of the target reaction [12]. This technique has been described for the sensing different species such as glucose [39], lactate [20] and ethanol [40] in sweat. In all mentioned examples, the used mediator was Prussian Blue with the specific enzyme for each species, ensuring good selectivity to the device.

Despite the techniques of amperometry and potentiometry being the most used techniques in the development of wireless wearable electrochemical sensors, other techniques have been reported, such as square wave anodic stripping voltammetry (SWASV) [41], cyclic voltammetry (CV) [42] and differential pulse voltammetry (DPV) [12]. An advantage of voltammetric techniques in relation to amperometry is the possibility of coupling pre-concentration techniques to trace levels, thus obtaining better detection limits.

Although electrochemical sensors are promising analytical tools in the development of wearable devices with wireless communication, there are still several requirements to be addressed to achieve an ideal architecture, such as: the type of biological fluid sampling -(which can be sweat, saliva, tear, interstitial fluid and breath), the substrate for the construction of the platform -(needs to have flexibility, high mechanical resistance and biocompatibility), sensing materials, applicability accessories, electrode fouling and/or drift and power. Issues such as the need for calibration and device stability are essential for its optimal performance. It is also crucial that the sensor be free of external interferences from different sources [43]. Besides that, it is necessary for the construction of wireless wearable sensors to incorporate a flexible and active electronic system, such as transistors and integrated circuits for data processing and transmission for wireless communication systems $[26,32,44]$.

Several studies have shown that electrochemical sensors can be structured on different platforms such as glasses [20], bracelets [45], rings [13], gloves [15] embedded in fibers or cloths [46], temporary tattoos [40] on the skin and contact lenses [47] and despite the great advances in their knowledge and use, this 
field has experienced unbalanced advances in research and development [20,31]. The acceptance of this wearable sensor technology needs the creation of products that can be really integrated into user's lifestyle.

\section{Sampling with wearable sensor}

One of the main requirements for the development of wearable electrochemical sensors for continuous monitoring of physiological parameters is how the biological fluid will be sampled, in order to be concomitant with the sensing. From this configuration it is possible to classify the platforms in two ways: minimallyinvasive and noninvasive [48,49].

For minimally invasive devices there are some controversies about their definition, despite containing the sensing and sampling sets coupled. The most common definition is that they are types of devices that penetrate an external layer of the body such as the skin or internal epithelial tissues, like the nasal mucosa or the intestine in less than $1 \mathrm{~mm}$ and do not require a trained personal doctor for its application. Interstitial fluid (ISF) is the most accessible body fluid in a minimally invasive manner and contains chemicals in similar concentrations as blood, like glucose and ethanol, with less content of proteins, offering therefore a wide range for clinical application. This fluid bathes the epidermal tissues $(<1 \mathrm{~mm}$ below the surface of the skin) and can be analyzed, extracted, and accessed in situ trans dermally through near-infrared spectroscopy, ultrasound or microneedles, thus offering a new set for sampling $[48,50]$.

Preliminary studies have shown a needle-type biosensor with integrated RF capability to monitor cholesterol [51]. However, a more adequate approach is the use of micro-needles, allowing the miniaturization of the device. Some studies show the use of microneedles in the electrochemical device for detection of glucose and lactate [52]. Recently, Mohan et al. developed a skin-worn electrochemical sensor array used for continuous real-time monitoring of subcutaneous alcohol at the ISF. The device was consisted of an assembly of pyramidal microneedles integrated with $\mathrm{Pt}$ and $\mathrm{Ag}$ wires, each with a microcavity that was modified with the enzyme alcohol oxidase (AOx). The microcavity present in the microneedle array lends to create a stable enzyme layer without affecting its skin penetration capability. With this type of sensor, it is possible to couple a wireless system for then develop an alcohol minimally-invasive real-time remote monitoring device in individuals while eliminating blood sampling complications [53]. The measurements obtained by this method can be corrected due to the time lag between variations in blood and interstitial levels via validated compartmental models, and despite being a promising approach, there are several improvements to be made in terms of sensing platform such as durability and sensitivity. Another issue to be evaluated in this type of system is that despite being minimally invasive it can cause bruising and skin irritation, tending to be inconvenient and uncomfortable [51].

Regarding noninvasive sensors, they offers the opportunity to not require any drilling or incision procedure, and in addition, it can detect analytes and metabolites in different biological fluids such as sweat, saliva, tears and epidermal interstitial fluid [54,55].

Tear is a very complex extracellular fluid that contains proteins, electrolytes and metabolites. Currently, its use in the construction of noninvasive electrochemical devices is directed to the detection of glucose [54]. As an example, Keum et al. developed an intelligent contact lens system, being a noninvasive wearable device with electrochemical detection for glucose monitoring in tears. The device was built on a biocompatible polymer fabricated by the chemical cross-linking of silicone hydrogel precursor solution containing a PET film, flexible electrical circuits and a microcontroller chip for real-time biosensing, wireless power management, and data communication [47]. Despite the technological advancement, a major challenge in wearable eye detection is obtaining an adequate energy source.

Saliva is an another complex biofluid that contains many components present in the blood such as enzymes, hormones, antibodies and so on. Thus, it is possible to monitor the emotional, hormonal, nutritional status of the human body $[56,57]$. The detection in this type of biofluid has been demonstrated for the detection of urea [58], glucose [39], uric acid [22], lactate [59] and lithium [60]. Despite being a very promising type of device, several challenges still need to be overcome, such as the low concentration of biomarkers in saliva compared to the blood and surface biofouling interference from salivary macromolecules [27]. 
In order to obtain the interstitial fluid in a noninvasive way, the combination of the reverse iontophoresis technique and biosensing in a single device has been demonstrated. Reverse iontophoresis is based on the extraction of interstitial fluid trans dermally. This method consists of applying a small controlled electric current to the skin $\left(<0.5 \mathrm{~mA} \mathrm{~cm}{ }^{-2}\right)$, with the aim of increasing the transport of low molecular weight substances through the skin, such as ions and neutral polar compounds. Due to the application of electric current, the transport rate of the compounds is greater than their passive permeabilities, and the main transport mechanisms are electromigration and electroosmosis, where the contribution fraction of each mechanism is dependent on the physicochemical properties of such as the need for calibration, not causing discomfort or irritation to the skin due to the current or potential applied to the fluid extraction. In addition, there is a limitation on the amount of fluid extracted and a long extraction time is not suitable for biosensing.

The development of wearable electrochemical sensors has been largely directed towards the detection of species present in sweat. Several components of sweat have been used as target analytes to validate this design [61]. The development of wearable electrochemical sensors has been largely directed towards the detection of species present in sweat. Among these components are sodium [34], potassium [20], calcium and $\mathrm{pH}$ [37], lactate [62] and ethanol [40], among others [61]. The advantages of choosing sweat as a biofluid in noninvasive wearable systems include the possibility to be sampled at very low fluid generation rates and external contamination, as well for continuous access in addition to the possibility of being stimulated on demand with local iontophoresis. In contrast, its use still raises several challenges such as being irregular without iontophoretic stimulation, old sweat can mix and contaminate new sweat, changes in skin $\mathrm{pH}$ and low sample production rates [63].

A significant effort in research has been reported in the literature for noninvasive devices so that the platforms provide both the sensing and the possibility of data transmission. A major view over the possibilities for different wearable electrochemical devices can be seen in the section "Application fields for wireless wearable electrochemical devices".

\section{Materials and methods employed to construct wearable electrochemical sensors}

For the construction of a wearable sensor, it is widely known that the material of the platforms needs to be biocompatible, functional/active and with low manufacturing cost. In addition, for substrates that are in contact with skin it is necessary that they are flexible, with high density, robust, and present high mechanical resistance [64].

Several works have been reported using extensible materials as substrates, such as elastomers and elastomer composites with metallic fillers, which provide mechanical robustness, high device density, and scalability. The use of substrates based on polymers is given due to unique characteristics such as greater mechanical resilience and possibility of an adequate conformational adjustment between the contact surface and the sensor, in addition, it offers lower noise values in the response of the analytical signal. An example is the silicon elastomer polydimethylsiloxane (PDMS), which has been widely used in wearable sensors, and has the characteristics of biocompatibility, high tensile strength, hydrophobicity and is not flammable [38].

Recently, Lee et al. [65] presented an extensible electrochemical sensor for glucose monitoring based on PDMS with polyurethane nanofibers, incorporated with cotton fabric. The electrodes were formed directly on the PDMS substrate, in which the working electrode and the counter electrode were composed of nanoporous gold and the reference electrode by an $\mathrm{Ag} / \mathrm{AgCl}$ layer. In addition, the sensor was incorporated into a microfluidic system to perform sweat collection for subsequent measurement of glucose levels. This on-body sensing shows great potential for continuous monitoring of metabolites, not only in sweat but also in other body fluids and also prove to be a great prototype for the incorporation of wireless systems. PDMS was selected as the best choice of flexibility stretchable substrates, and despite being a promising material, the use of PDMS has disadvantages like poor thermal stability due to the limitation at preparation temperature of the electrode and long-term instability due to its high permeability $[38,66]$. 
Others polymers have been used as options for building wearable devices such as polyimide (PI), parylene, poly(methyl methacrylate) (PMMA), polyurethane (PU), polyurethane acrylate (PUA), polyethylene terephthalate (PET), polyethylene naphthalate (PEN), poly(3,4-ethylenedioxythiophene)poly(styrenesulfonate) (PEDOT:PSS) polystyrene-block-poly-(ethylene-ran-butylene)-block-polystyrene (SEBS). Among those mentioned, PI and PET are widely used as a flexible bioelectronics material in biosensor integration technology owing to their good performance and user comfort. PET exhibit excellent deformability and optical transparencies and PI plays important role due to its high mechanical strength and applicability as support layers for skin sensors [38,61,67,68].

Other materials have been widely used for the construction of wearable systems, such as fibers, paper and textiles [66]. Being flexible and widely used in our daily life, textiles such as wool, cotton, and nylon have been extensively exploited as the substrate for integrating various electrochemical biosensors, even as paper that can be readily and rapidly modified with biomolecules and nanomaterials for electrochemicalsensing applications [33,69].

The materials used as well as the manufacturing techniques for the wearable devices depend on the desired application, such as the biological fluid and analyte/metabolite of interest and the type of sensor. There are different manufacturing methods described in the literature, including soft-lithography, photolithography, electron-beam evaporation, inkjet printing and screen-printing [70,71]. Among the aforementioned methods, the screen-printing has been widely used in the manufacture of electrochemical wearable devices due to features such as the versatility of modern thick-film, fabrication techniques enable large-scale manufacture in different geometries, low cost, robustness, and suitable electrochemical performance. In contrast, the lithographic methods are capable of producing high-performance electroanalytical devices, however, they have the high cost as a major disadvantage [70].

Conductive electrodes are the main components in wearable electrochemical sensors, so it is extremely necessary that the electrodes have mechanical flexibility and stability. The ideal electrode material must have characteristics such as robustness, high conductivity, low resistance, low processing temperature, flexibility and extensibility [66]. In addition to all the challenges imposed on the electrode material, there is still the incompatibility of properties and foundational mechanics that could appear during stretching [67], thus disabling the sensor due folding of the device $[61,72]$.

The most used materials for the construction of flexible electrodes are carbon nanomaterials and metallic nanoparticles. Nanomaterials such as metallic nanoparticles (NPs), nanowires (NWs) and carbon nanotubes (CNTs) have been used, due to their thermal, mechanical and electrical properties, in addition to offering different surface areas. NPs and NWs are excellent conductive materials providing high mechanical flexibility and electrical conductivity $[38,66,73]$. Carbon materials such as carbon black (CB), CNTs and graphene have excellent properties. The limitation of CB is the difficulty of dispersion in elastic or solvent matrices due to its aggregation. CNT features excellent intrinsic conductivity, high optical transparency and thermal stability; and several of graphene-based electrodes as sensors have been studied due to material characteristics such an excellent electron mobility, ultrahigh strength, and low contact resistance with organic electronic devices [74].

Among the nanostructured metals, gold nanoparticles (AuNPs) are being the most common in flexible electrodes [38], moreover to the use of AgNWs or AgNPs on flexible platforms due to its optical transparency, high electrical conductivity and high mechanical flexibility [75]. Silver nanoparticles are well known as an effective antimicrobial agent and already used widely in consumer products, such as clothes, shoes and toys. Some studies had shown that AgNPs are able to enter the cells, whereas for the corresponding metal ionic species either no or a relatively low penetration could be seen. As well no toxicity was observed for AgNPs due to low release of silver ions within short time periods, so, being a safe substrate for electrode printing in wearable sensors [76]. Although some concerns need to be addressed for other metal nanostructures, considering its potential toxicity for human health and environment and the lack of studies demonstrating its safety. 
In addition, materials such as printing inks have helped to promote advances in printing technology on different types of substrates [66]. The printing inks used to build flexible electrodes are basically composed of fillers, binders and additives. Fillers are the active component of the paint that provides the characteristic features needed for each application and can be metallic, ceramic, organic or a combination nanomaterial, such as nanosheets, nanowires and nanoparticles. Among these materials, carbon-based inks have received great prominence due to the numerous properties of carbonaceous nanomaterials such as high surface area and conductive properties [77].

The design of solid-state reference electrodes without a liquid junction, the called pseudo-reference is a crucial point in the construction of wearable sensors. The purpose of the reference electrode is to provide a stable potential relative to the solution, which the potential of the working electrode is referred to this potential [78]. The easiest and most common employed type of reference electrode is the Silver/Silver Chloride $(\mathrm{Ag} / \mathrm{AgCl})$ pseudo-reference electrode. This electrode has several favorable traits, such as fast reaction kinetics and a lower toxicity than calomel-based reference electrodes $[79,80]$.

The main difference between the $\mathrm{Ag} / \mathrm{AgCl}$ pseudo-reference electrode and the normal $\mathrm{Ag} / \mathrm{AgCl}$ reference electrodes is that the $\mathrm{Cl}^{-}$concentration is not maintained constant by a liquid compartment enclosing the solid electrode, making the electrode susceptible to oscillations of its potential when the $\mathrm{Cl}^{-}$concentration in test solution varies. Thus, it is very important that the chloride ions concentration in the test solution, be kept constant to provide a stable and reproducible potential. This concentration of chloride ions must be at moderate concentration to ensure that the small amount of chloride ions present in the analyzed samples can be negligible and does not alter the accuracy of the pseudo-reference electrode [80].

Although several technological innovations have been made in relation to flexible substrates and materials, there are still challenges in the construction of this type of device such as incompatibilities in properties and also in basic mechanics causing the deactivation of the sensor [61].

\section{Calibration, long-term stability and sensitivity of the wearable electrochemical sensor}

Despite the significant progress in the development of electrochemical bioelectronics for wearable devices, some key challenges need to be addressed, considering that the continuous exposure to a living biological system increases complications of the sensor [81]. The physical and mental traits of a human body constantly change and behave differently depending on time, age, environment, and circumstances. For example, the sweat rate changes under stress, coercion, intense physical activity, and so on. Other factors such as the fluid $\mathrm{pH}$, volume, and flow rate could also potentially affect the accuracy of in situ monitoring and suitable detection mechanisms need to be introduced to achieve better accuracy for wearable devices. Due to the difference of the analyzed biofluids, it is also necessary that sensors can accurately measure compositions at small volumes and have minimal calibration with fast response time, long-term stability, extended lifetime, and durability [54]. Furthermore, minimal drift, high sensitivity and selectivity, anti-fouling, internal calibration strategies, repeatability as well as mechanical reliability and system robustness need to be addressed when used continuously in wearable devices [70]. Also, the amount of sample and sampling strategies are problems that need to be circumvented too, as well as mechanical material degradation or failure due to stress [7].

An important aspect to consider is the quantification approach used for wireless monitoring with wearable devices. It is important to have in mind that electrochemical methods are not absolute, and their results need to be compared with a calibration curve or performed by the standard addition method. However, the last one is not viable for in vivo analysis because it implies contaminating the individual/sample. Therefore, the usual strategy relies on sample collection and conduction of comparative ex situ analyses to correlate the results obtained by the on-body sensor and that of the collected sample. This correlation in some cases can be performed considering a population mean, but ideally it should be customized/personalized to take into account the differences between individuals (metabolism, excretion, sample production, temperature, and so on) [26]. A calibration-free approach is an important example of how calibration issues can be overcome, also for other application areas [54]. As different detection methods usually have varying 
susceptibility against the same interference, rational response can be estimated more reliably from the ratio of both single responses. Unfortunately, calibration-free approaches are few and might work, depending on the environment, but most have still not been tested for very long-term functionality. Self-calibration, incorporation of calibration reagents or reference items maybe the best solution for an accurate calibration but also become less realistic the more sensor entities shall be deployed, considering cost, replacement or maintenance efforts, and stand time of reagents [26]. The use of orthogonal approaches (colorimetric/ potentiometric/fluorescence/electrochemical/volumetric modes in the same sensor) [82] could also be an important alternative for calibration issues, as well the use of amperometry, chronoamperometry and exhaustive coulometry as self-calibration strategies [26].

Eliminate fouling/passivation of the electrode surface is one of the most challenging aspects of electrochemical wearable devices [70]. The nonspecific adsorption (fouling) is one of the first primary steps to diminish long-term stability in wearable devices. Some studies have shown that serum albumin and other endogenous protein or biomolecules fragments can adsorb onto the electrode surface diminishing the diffusion of analytes of interest to the sensor surfaces and making the detection impossible. For that reason, numerous materials have been developed to form a protective coating to reduce nonspecific adsorption on sensors, as well as the use of some electrochemical techniques to prevent this phenomenon. Some materials used for anti-fouling include protective and selective membranes, with durable solid membranes, such as monolayer protein [83], Nafion [84], polyethylene oxide (PEO) [85], poly(ethyleneglycol) (PEG) [86], oligo(ethylene glycol) (OEG) [87] and polycarbonate [88]. Zwitterionic polymers containing both cationic and anionic groups on the same monomer residue have been also proved to be biocompatible and multifunctional to prevent fouling in biosensors [89]. A study showed that the zwitterionic polymer coatings reduce nonspecific protein adsorption not only from single protein solutions such as BSA, fibrinogen, antibody and lysozyme, but also from complex media, such as undiluted blood plasma [90]. Some approaches to shield the sensing element and sensor from interferents with filters [91], and cleaning/ renewing of the sensing element/membrane (with irradiation, heat or UV light) [92,93] are also realistic contributions toward the long-term reliable operation. The use of specific electrochemical techniques has also shown that fouling could be prevented in electrode surface when fast scan cyclic voltammetry (FSCV) or chronoamperometry were used. Due to the fast scan rate, the FSCV limits the diffusion distance of the charged molecules to the electrode and minimizes electrode fouling in vivo [50]. Amperometric signal modulation is another strategy, shown years ago by Rocklin et al. which enabled a cleaning of the electrodes [94]. So, this approach can be an interesting alternative or be imagined as an additional measure to reduce fouling effects.

Operational challenges of wearable electronics represent another paradigm, where special conditions and pretreatments of the sensors are desired to enhance the sensitivity, selectivity, accuracy, limit of detection, and so on [81]. Some of these treatments such as chemical treatments to restore the initial stable values cannot be applied while sensors are installed on wearable devices. The simultaneous monitoring of multiple analytes is also challenging as cross-talk between different sensors influences their selective detection. Increasing the density of sensors, data processing units, and wireless communication channels would require more power and is, therefore, challenging when trying to maintain the same level of operation for long durations. Besides that, some challenges for real application of wearable sensors have to be addressed for continuous growth of this area, especially when nonenzymatic approaches are used because strategies to increase selectivity and sensitivity have to be proposed for real applications [70]. The use of biological recognition agents and (bio)chemical modification of the electrode surface to improve the selectivity and sensitivity are almost mandatory to allow direct on-body sensing, as well as the coupling of additional strategies and devices to collect, preconcentrate, and incubate the biofluids during on-body measurements. The majority of developed wearable sensors are functionalized with specific enzymes to enhance the selectivity and sensitivity toward a specific analyte and they commonly rely on affinity-based recognition which is hard to regenerate in vivo with current technologies [81]. Some common metabolites, such has glucose or lactate have their detection based on this approach. However, electroactive molecules 
could be directly detected considering the loss or donation of electrons on the electrode surface when a redox potential is applied to the sensing electrode. Usually, linear sweep voltammetry (LSV) and cyclic voltammetry (CV) are employed as the first strategy to evaluate the electrochemical behavior of these electroactive molecules on a specific working electrode due to the simple and rapid operation. However, in electrochemical detection, these methods result in low sensitivity due to a large background current arisen from charging at the electrode surface [50]. Pulse techniques, such as DPV or square wave voltammetry (SWV) could be utilized as attractive approaches to decrease the limit of detection enhancing the sensitivity. In such techniques, the currents are recorded before the beginning and at the end of the potential pulse, and the current difference is monitored concerning to the voltage, minimizing background current. Owing to the minimized effect of the charging current, high sensitivity down to nmol levels can be reached, making it possible to use flexible and wearable devices to monitor ultralow levels of electroactive molecules in body fluids or other matrixes [95]. Some other approaches are related to enhancing the sensitivity of electrochemical wearable devices, considering the nature of the modified working electrode. Instead of directly using printed metallic or carbon electrodes, nanomaterials functionalized or modified electrodes may be utilized to increase the electroactive area and the sensitivity of the direct electrochemical detection through different electrochemical techniques. However, the biocompatibility of those materials and substrates is another major concern for wearable electronics, especially for sensors mounted on the skin/epidermis. The physical, mechanical, and chemical properties of these materials and substrates need to be matching to avoid thermal, electrical, and multi-layer integration mismatches. Furthermore, although nanomaterials play an important role in flexible electrochemical bioelectronics toward improving the sensing performance, their potential toxicity and biocompatibility need to be carefully evaluated [50].

Although some of these related approaches have distinct advantages on simplicity, sensitivity and low cost, major challenges on selectivity and biofouling need to be overcome in order to achieve continuous, stable, and selective measurement in vivo. To address these challenges, new material innovations and quantification strategies are strongly desired. Owing to its high portability, and low cost, the development of new strategies for electrochemical sensors with high sensitivity and selectivity hold great promise toward point-of-care and wearable applications.

\section{WIRELESS TECHNOLOGIES FOR WEARABLE SENSOR Communication Protocols}

Wearable sensors are expected to be able to communicate wirelessly with other devices, such as a smartphone. Various types of wireless technology and networks allow these devices to send data to each other without cables. There are a number of different wireless technologies that can be implemented in hardware products for the loT. Such technologies include Bluetooth, ZigBee, RFID, NFC, which are the most common for the development of wireless wearable sensors. Each of these wireless protocols has its own specific advantages and limitations. Selecting the right one when developing a wearable device is an important step, as it affects the system's performance and features, such as size, communication range, data transfer rate, and power consumption [2].

The wireless protocols can be classified into active and passive based on the role of power supply required to operate the devices. The active ones require power to operate, for instance Bluetooth and ZigBee, whereas the passive ones do not rely on power (RFID and NFC). Active wireless systems can both transmit and receive information over a distance, meaning they need a power source, typically a battery. So, sensors based on Bluetooth and ZigBee, for example, have a transceiver which communicates with a reader device or other sensors in a network with a range of 10 up to 100 meters. Based on the application's requirements of range and data rate, the energy consumption can be adjusted, but the system needs an energy supply to power both the data transmission and sensor circuitry [2]. One recent example of use of a low-power energy-efficient Bluetooth microcontroller (Texas Instruments CC2640) is an eyeglasses-based sensor merged with a fluidic sampling for tears alcohol analysis [96]. The platform was composed of an integrated microfluidic system, attached to the eyeglasses, to guide the tear sample to the electrode, which was based on the enzyme alcohol oxidase. 
In contrast, passive wireless systems, like RFID and NFC, communicate with a reader device only when it requests information, by means of modulation of the electromagnetic field generated by the reader. $A$ disadvantage is that the reader must be in close proximity, just a few centimeters, $<5 \mathrm{~cm}$ (NFC) up to several meters < $15 \mathrm{~m}$ (RFID), making the range very short when compared to active systems. Also, since there is no power source, data cannot be logged autonomously. This makes the system rather inconvenient for wearable applications, once it requires human intervention to bring the reader close to the sensor for data collection, limiting the prospect of having autonomous wearable sensors [2]. Despite the disadvantages, RFID/NFC remains a viable option due to its low power requirements. An example of using NFC protocol was demonstrated in the development of a sweat $\mathrm{Na}^{+}$sensor, build on a flexible printed circuit board (PCB), becoming a fully integrated wearable skin patch. Potentiometric data from the ion selective sensor was transmitted to a smartphone using NFC. The sensor was passively powered by the smartphone, so it had no battery. Its operational lifetime is only dependent on the sensor chemistry [97]. Due to increasing smartphone ownership and easy availability for developing tools and hardware, the two most explored wireless technologies in wearable sensors are Bluetooth [22,98,99] and NFC [100-103]. In cases where continuous connectivity is not a requirement, the data can be logged locally on the sensor platform and later requested by a device such as a smartphone. One important aspect of designing a wireless sensor system is thinking about what data to show the user. Sending all the information generated by the sensors would be both unhelpful and wasteful, since wearable devices often have power restraints. Therefore, providing only relevant information that can be easily understood by the user is a desirable goal from an energy consumption standpoint and also user-friendliness.

\section{Power Sources for Wearable Sensors}

Wearable devices often performing tasks such as data analysis, communication, and detection simultaneously, it is of no surprise that their power consumption is of great concern. To help minimizing the problem, techniques such as modulating the device's sampling frequency can be employed with great effect. The use of low-power energy-efficient electronics is another approach. Nonetheless, the development of better and alternative power sources has become essential to address this issue. Thus, research is being carried out on solutions such as wearable batteries [104,105], biofuel cells [106,107], solar cells [108], supercapacitors [109-111], and piezoelectric/triboelectric energy sources [112-114], each with its own benefits and drawbacks. Energy extracted from body motion, sweat or friction could also be used as an alternative to the traditional batteries.

The most common way to provide power to wearable devices is through a battery. Lithium-ion batteries have long life cycle, low self-discharge rate, and high energy efficiency. Their disadvantage is their weight and size, because they are usually heavier and bigger than the device that they are powering. Also, their body is rigid, rendering them unsuitable for skin-interfaced devices. This is addressed in recent developments in flexible and stretchable batteries [115-117], although their performance is not yet on par with their conventional counterparts. Another important advancement is the development of an ultrafast rechargeable battery [118].

Recently, supercapacitors have been considered as an alternative, given their safety and capacity for fast charge and discharge [119]. They can be used together with energy harvesting techniques to store and provide power as needed [120]. However, there are still complications to be solved, such as improving energy density, which is affected by multiple factors, including electrode materials, binder, and electrolyte [121]. In addition to the improving efficiency, some researchers are focusing on developing transparent epidermal supercapacitors, which would improve optical interfaces to the skin. One example uses an Ag/Au/ polypyrrole core-shell mesh based on a nanowire on a silicone substrate as the supercapacitor electrode. The system shows good transparency across the visible range ( $73 \%$ at $550 \mathrm{~nm}$ for 2 layers of the mesh) and good charging/discharging cycling properties $\left(580 \mu \mathrm{F} \mathrm{cm}{ }^{-2}\right.$ at current density of $\left.5.8 \mu \mathrm{A} \mathrm{cm}^{-2}\right)$ [122].

Other novel alternatives are wearable solar cells and biofuel cells. Biochemical energy from biofluids, such as blood, tears, and sweat, which are always available and are rich in metabolites, can be used in 
biofuel cells to generate electricity. Since the flow of biofuel is controlled by human physiology, continuous generation of constant power is difficult. One example is a screen-printed highly stretchable (500\%) biofuel cell. The device uses a special stretchable ink based on carbon nanotubes as the conductive component. The cell displays a maximum power density of $\sim 50 \mu \mathrm{W} \mathrm{cm}{ }^{-2}$ at a voltage of $0.25 \mathrm{~V}$ in the presence of 20 $\mathrm{mM}$ glucose [122].

Harnessing energy from light is another tough challenge. Even though the field is advancing, there are still major challenges ahead, since solar energy is a very low-density power source. Thus, suitable levels of power require a panel with a large surface area. Also, the highest conversion efficiency is achieved when sunlight reaches the panel perpendicularly. Taking into account the shape of the human body, its constant motion and the sun's motion, only a negligible fraction of sunlight will fall normal to the panel, converting a low fraction of sun light into effective energy for the device. Given these challenges, researchers are exploring ways of improving conversion efficiency [123].

\section{Data Analysis and Privacy}

The emergence of the so-called big data for health-related fields like wireless (bio)chemical sensors raises questions about privacy, security, and data ownership [124]. Extensive amounts of highly personal data will be generated by physical and chemical sensors, and also by many new smart devices, networks, and software applications. Data privacy is, therefore, of crucial importance in the healthcare domain and its security should be enforced at every step of the system, including at the sensor level at which the data is collected [125].

As more people rely on wearable sensors, they become exposed to potential security breaches. Providing the wearer with the most relevant analytical information in a simple way is important for widespread adoption of wearable technology. This involves data mining to analyze and filter relevant information before presenting it to the user. However, current data mining algorithms will not be able to cope with the amount of data that wearable sensors are expected to output [126]. Efforts to address these problems are being performed with new algorithms and expanding data mining protocols to work with heterogeneous information [127]. If wearable sensors are able to output information at high data rates, they must have powerful data storage and processing capability. This is challenging given the constraints associated with a compact wearable device. Cloud computing could be a way of mitigating this problem [128], removing the need for dedicated electronics for storing and analyzing raw sensor data. However, remotely handling the data must go hand-in-hand with security measures.

\section{APPLICATION OF WIRELESS WEARABLE ELECTROCHEMICAL DEVICES Health and Fitness monitoring}

Over the past few decades, the tremendous advance in electronic, medicine, chemistry, biocompatible materials and nanomaterials has led to the development of technologies that provide rapid and patientcentred diagnostics, especially for those with limited access to health services, while conventional disease diagnostic tests commonly used in laboratories and hospitals are time-consuming and costly, and require highly trained personnel $[50,81]$. More recently, a considerable progress in "epidermal electronics" area, including miniaturized wearable, implantable and flexible devices has been reached on medical and sport field enabling diagnosis and prognosis through small sensors and biomedical devices, greatly improving the quality and efficacy of health care, and the monitoring of physiological parameters for fitness and sport proposes. These flexible bioelectronics allows natural interaction between electronics and the soft human body and enables real-time and continuous health monitoring (e-Health) and transmission of biological data to the Internet for further processing and transformation into clinical knowledge [129]. This devices provide a continuous physiological status of individuals and personalized health profile to keep track of an individual's well-being $[130,131]$ and are becoming important for long-term health monitoring due to the increasing elderly population throughout the world [81]. Although it all started as a cost-effective alternative to deliver diagnostic strategies in the developing world, especially in rural, remote, and underserved 
communities, it has rapidly proliferated as a revolutionary tool that may enable virtual appointments between patients and doctors [132,133].

The current market for wearable electronics is still limited to tracking physical and vital signs from patients or users. The monitoring of human physiological activities such as body motion, respiration, heart rate, electrocardiograms, skin temperature, oxygen concentration and blood pressure are the most common and found in every smartwatch available on the market $[81,129]$. To provide a complete picture of the health state of an individual, it would be also very attractive to measure other physiological biomarkers, such as glucose, lactate, intra- and extracellular ions, and specific diseases biomarkers. Some recent studies are being conducted for the development of wearable hybrid devices that could simultaneously measure both chemical and electrophysiological parameters in a single epidermal patch $[50,134]$. Although these devices are mostly based on optical detection principles, an alternative can be the use of electrochemical assays through electron transfer during redox reactions for health markers monitoring $[54,70]$. In the following paragraphs, the main wireless wearable electrochemical devices used in health monitoring will be reviewed, given special attention to the different monitored analytes, dividing it in four main groups: glucose- and ion-selective-sensors, and sensors for organic compounds- and specific diseases. Some examples of wearable electrochemical devices for health and fitness monitoring are summarized in Table I.

\section{Wearable glucose sensors}

Glucose sensors are one of the most common biosensors related in literature. Due to the major problem of diabetes diseases caused by disorder or depletion of insulin leading to various major complications, the patient's glucose levels should be constantly monitored and controlled [135]. Therefore, attachable devices that monitor glucose to improve diabetes management and blood glucose control are very attractive, as they help the continuous real-time monitoring of patients for quick self-assessment $[9,81]$. Currently, interstitial fluid is the most used in continuous monitoring of blood glucose levels for its glucose correlation with blood glucose concentrations. Others physiological fluids such as urine, sweat, saliva, ocular fluid, and breath contain glucose biomarkers that could also be used for glucose monitoring $[81,136]$.

Numerous studies are related for glucose wearable sensors and the smart watches are one of the most popular types. GlucoWatch ${ }^{\circledR}$ biographer (Cygnus Inc., Redwood City, CA, USA) was the first device to have a commercially approval for noninvasive glucose monitor by the Food and Drug Administration (FDA) [137]. It works acquiring electrochemically information about glucose concentration extracted by reverse iontophoresis from skin interstitial fluid. The direct measure of glucose concentration on the human skin is a promising approach for the future devices. Lee et al. has created a wearable patch-type sensor made from graphene and gold to enable direct sweat analysis with a wireless connection to a smartphone using an Android application via Bluetooth [138]. These flexible devices used gold mesh and gold-doped chemical vapor deposition (CVD) graphene electrodes to ensure high conductivity, optical transparency and mechanical reliability for stable electrical signal transmission, with an internal interference elimination system: when the relative humidity is detected at the critical sweating point, the temperature and $\mathrm{pH}$ is measured and corrected at the same time. The developed wireless device shows also an interesting way for direct drug delivery system, once when a high concentration of glucose was measured, the internal heater dissolved the phase-change material and released metformin in a feedback percutaneous drug delivery reaction through biocompatible microneedles direct into the human body. Another study, conducted by Lee's Group developed a thin and stretchable microfluidic device that was made with nanoporous gold electrodes in a poly(dimethylsiloxane) (PDMS) substrate, enabling collection and accurate delivery of sweat from skin to the electrode surface, with excellent replacement capability. The integrated glucose sensor patch demonstrated excellent ability to continuously monitor the sweat glucose level with high accuracy and good skin adaption. For the on-body detection, copper wire leads were attached to the electrodes of the sensor patch with silver paste to connect them to a portable electrochemical analyser (EmStat Blue $3+$, Palm Instrument B.V.). This portable electrochemical analyser was then controlled wirelessly using a PStouch Android application (Figure 1A) [65]. Other examples for glucose wireless electrochemical sensors are summarized in Table I. 


\section{Wearable ion-selective sensors}

These sensors have one of the simplest forms of sensing modality as the response is determined by ion exchange/transfer processes at the selective membrane-liquid interface. With major developments of sensing materials chemistry, sensitive and selective sensors can be quickly achieved for ionic detection in biofluids. The selective membrane typically consists of ion-selective ionophores dissolved in complex polymeric matrix with high mechanical stability and decides the sensitivity and selectivity of the ion-selective sensors. Each of these layers is critical to produce high-performance ion-selective electrodes for long term usage in wearable devices. These wearable potentiometric sensors integrated into a conformal platform to achieve coherent structure and easy wearability depending on applications have been widely investigated for detection of a variety of analytes in different matrixes [50].

Currently, the most common wearable potentiometric sensors are ion-selective sensors for detection of small ions such as $\mathrm{Na}^{+}, \mathrm{K}^{+}$, and $\mathrm{H}^{+}$. Recently, a noninvasive wearable electrochemical device for continuous monitoring of ionized calcium and $\mathrm{pH}$ in body fluids using a disposable and flexible array of $\mathrm{Ca}^{2+}$ and $\mathrm{pH}$ sensors that interfaces with a flexible printed circuit board was developed by Javey's Group. The sensor was made with selective membranes for both ions supported over a PET substrate. The accuracy of $\mathrm{Ca}^{2+}$ concentration and $\mathrm{pH}$ measured by the wearable sensors was validated through inductively coupled plasma-mass spectrometry technique and a commercial $\mathrm{pH}$ meter, showing that the wearable sensors had high repeatability and selectivity to the target ions. Real-time on-body assessment of sweat was also performed, and the results indicated that calcium concentration increases with decreasing of $\mathrm{pH}$ [37].

Sodium ion is a potential biomarker for hydration status. In a study, the authors showed that sweat $\mathrm{Na}^{+}$ concentration increases abruptly after approximately $2 \mathrm{~h}$ of outdoor running when there is no replenishment for lost water. Among various ions found in human body fluids, detection of $\mathrm{Na}$ ions has been the most prominent in wearable research due to its presence at high concentration in biofluids and physiological importance for maintaining fluid and electrolyte balance [34]. A potentiometric sodium ion sensor was developed by Alizadeh et al. depositing a chloride membrane into the internal layer of electrochemical deposited poly (3,4-ethylenedioxythiophene) (PEDOT). The solid-state $\mathrm{Na}^{+}$ISE was based on the calix[4] arene tetraester $\mathrm{Na}^{+}$ionophore as well as the reference electrodes (RE) were fabricated using a $175 \mu \mathrm{m}$ PET substrate onto which conducting carbon and dielectric insulating layers were screen-printed using a DEK 248 printer. The developed sweat patch and associated electronics module were monitored remotely via Bluetooth for the detection of sodium concentration during a session of exercises [139].

Other flexible and attachable body fluid monitoring smart system was developed by Shen Group. In this work, they reported a wearable self-powered-like sweat monitoring system with integrated microsupercapacitors (MSCs). The monitoring system is composed of ion selective membrane based [ $\left.\mathrm{Na}^{+}\right]$and $\left[\mathrm{K}^{+}\right]$sensors, and $\mathrm{NiCo}_{2} \mathrm{O}_{4}$-based $\mathrm{MSCs}$ as the power source of the sensor arrays, displayed an excellent electrochemical performance with high sensitivities of $0.031 \mathrm{nF} \mathrm{mM}{ }^{-1}$ for $\left[\mathrm{Na}^{+}\right]$and $0.056 \mathrm{nF} \mathrm{mM}^{-1}$ for $\left[\mathrm{K}^{+}\right]$. By further integrating with wireless transmission technology (WiFi), the system could easily and accurately realize the real-time monitoring of perspiration [140].

Chloride is an important biological parameter for cystic fibrosis diagnosis [141]. Considering that the sweat $\mathrm{Cl}^{-}$has been the gold standard for this diagnosis, researchers developed a skin-worn wearable platform for local sweat extraction and $\mathrm{Cl}^{-}$monitoring using flexible ion selective sensors. A device developed by Javey's Group allows a simultaneous detection of sweat rate based on the change in impedance between two parallel metal electrodes and monitoring of ion $\left(\mathrm{H}^{+}, \mathrm{Na}^{+}, \mathrm{K}^{+}, \mathrm{Cl}^{-}\right)$concentration with an ionselective electrode. The signal from the impedance is sampled by the on-chip analogical-to-digital (ADC) converter, and a discrete Fourier transform (DFT) algorithm is used for impedance calculation. A 16-bit ADC (LTC1864) is used to measure the potential difference between working and reference electrodes. Both parts are controlled by a microcontroller which sends data to Bluetooth module via UART protocol. Finally, the Bluetooth module wirelessly transmits the data to mobile phone interface for display. The incorporation of sweat rate monitoring further assists in the understand of inter-related sweat parameters due to secretion rate (Figure 1B) [142]. 


\section{Wearable sensors for organic compounds}

Besides glucose, other organic compounds present in body fluids are closely related to human health and play important roles in the regulation of metabolism and are vital for maintaining the health of the entire human body. So, wearable biochemical sensors for detecting such organic compounds are really in need for continuous monitoring in order to assess human health and wellbeing since adverse effects occur in the absence or deficiency of these biomarkers. Many of these sensors are based on corresponding enzymatic electrodes, which are similarly fabricated as enzymatic glucose sensors, but since some analytes have good electrochemical activity a direct monitoring of such biomarkers could be conducted without an enzyme mediator.

Uric acid (UA) is an important final product of purine metabolism in human body. If the excretory system of uric acid is not working normally, an excess of UA is detected in human fluids, which leads to change in the $\mathrm{pH}$ of the fluid and affects the normal function of human cells. Some diseases such as gout occur if UA content in the body is neglected for a long term. In 2015 a mouthguard enzyme-based biosensor for uric acid was proposed by Kim et al. The enzyme (uricase)-modified screen-printed electrode system was integrated with anatomically miniaturized instrumentation wireless electronics composed by Bluetooth 4.0 link for data transmission. The mouthguard amperometric biosensor system offers high sensitivity, selectivity, and stability towards uric acid detection in human saliva, covering the concentration ranges for both healthy people and hyperuricemia patients [22].

Neuro biomarkers like stress indicators were also explored by some authors [143]. Parlak et al. also introduced an integration of an electrochemical transistor and a tailor-made synthetic and biomimetic polymeric membrane for selective molecular recognition of human stress hormone cortisol. The sensor and a laser-patterned microcapillary channel array were integrated in a wearable sweat diagnostics platform, providing accurate sweat acquisition and precise sample delivery to the sensor interface. The device was controlled using an Arduino Uno R3 microcontroller unit, which was used to power the individual components as well as to acquire and report detection data [144].

Lactic acid (LA) is a chemical substance produced in the glycolytic system and is known to be closely related to physical activity in anaerobic exercise such as muscle training. Blood lactate is already widely used in evaluation of training intensity in professions sports but sweat is becoming an interesting alternative for biological lactate monitoring in athletes and patients. A wearable electronic sensor capable of simultaneously measuring lactate, hydrogen ions, and sodium ions in human sweat through temperature sensing for internal calibration, equipped with microfluidic sampling and wireless reading electronics was proposed by Anastasova et al. The amperometric-based lactate sensor consists of doped enzymes deposited on top of a semipermeable copolymer membrane and outer polyurethane layers. For data acquisition, custom wireless sensing electronics based on the nRF51822 (Nordic semiconductors) IC with Bluetooth Smart wireless transmission were employed. A sensor interface was designed with a LT1638 (Linear Technologies) operational amplifier for measurements of the lactate sensor. An Android application was developed to capture the data from the wearable sensors and displays on other devices, like smartphones or tablets. A correlation between lactate and exercise frequency in sweat was observed by the authors once lactate concentration increased with a higher level of exercise effort [145].

Future efforts towards continuous lactate monitoring will focus on miniaturization and integration of the electrochemical circuits and electronics for data acquisition, processing, and wireless transmission, as well as critical assessment of all potential toxicity and biocompatibility concerns.

\section{Wearable sensors for specific diseases}

Despite the monitoring of some biological analytes in body fluids for healthcare, the impressive advances in the development of wearable sensors are allowing the researchers to perform clinical diagnoses in realtime based in specific biomarkers for a disease, without sophisticated instrumentation requirements. The specific biomarker analysis is one of the cornerstones of medical evaluation and the use of wearable devices has demonstrated the potential to become a fundamental medical tool when rapid, sensitive, and user-friendly disease diagnosis in non-laboratory environments is required. 
Considering the advances reported in the last few years in point-of-care (POC) devices integrated in wearable systems, a noticeable increase in the number of publications on biosensors for specific diseases detection has been observed. These devices can provide a multiplex detection of different biomarkers in a small volume of sample or the screening of numerous samples using a single chip, allowing the possibility of a personalized healthcare monitoring for each patient, making the diagnosis of some diseases simpler, cheaper and faster. Some PoC devices combined with microfluidic systems are already related to detect biomarkers at ultra-low concentrations for early diagnosis in asymptomatic patients of diseases such as cardiovascular disease, neurological disease, cancer, urinary tract disease, dengue fever [146], malaria, and recently also for SARS-CoV-2 [129].

The efforts in development of wearable devices for specific diseases detection can be seen in some previous works. For example, a portable electrochemical microfluidic paper-based immunosensor device

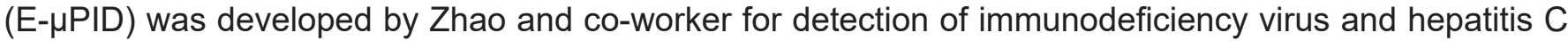
virus antibodies in serum, exhibiting high precision, sensitivity, and selectivity. The transmission of detection results to remote sites or health databases, via Internet or mobile networks, was related for the first time and can be used for telemedicine or patient's health-data storage and analysis. The platform was consisted of an electrochemical microfluidic paper-based immunosensor array (E- $\mu \mathrm{PIA})$ and a handheld multi-channel potentiostat, with a capacity of performing enzyme-linked immunosorbent assays simultaneously on eight samples within $20 \mathrm{~min}$. The circuit architecture of the potentiostat includes a microcontroller unit, a signal multiplexing/demultiplexing unit, a signal processing circuit (for converting an electrochemical current into a voltage), a $9 \mathrm{~V}$ battery and a Bluetooth wireless communication unit [147].

For Parkinson's disease (PD), several approaches have been developed for wearable monitoring systems during the last years, with detection of bradykinesia and tremor. Physical and cognitive parameters like tremors, balance dysfunction, motor rhythms and confusion are the most one monitored by wearable devices for PD diagnosis. These sensors do not use electrochemical or microfluidic principles, but the main concepts can be exploited in this manner. De facto, a microneedle sensor was developed by Wang's Group for continuous monitoring of Levodopa (L-Dopa) in interstitial fluids. L-Dopa is the most effective medication for treating Parkinson's disease, which is metabolized to dopamine. However, because dose optimization is currently based on patients' report of symptoms, which are difficult for patients to describe, the management of PD is challenging. So, a real-time and continuous monitoring device is important for an individual healthcare protocol for each PD patient. The reported sensing platform was made with different carbon paste electrode transducers assembled into a two-working electrode microneedle array for parallel independent electrochemical probing. While a direct electrochemical detection of L-Dopa was possible with SWV, a second microneedle electrode used chronoamperometric measurements for tyrosinase (TYR)based biocatalytic detection (Figure 1C). The designed biosensor used an Ag wire reference electrode, and no counter electrode was used. The new sensor device displays an attractive analytical performance with high sensitivity, a low detection limit, high selectivity, and good stability in artificial interstitial fluid. The attractive analytical performance and potential wearable applications of the microneedle sensor array was demonstrated in a skin-mimicking phantom gel as well as upon penetration through mice skin [148]. 


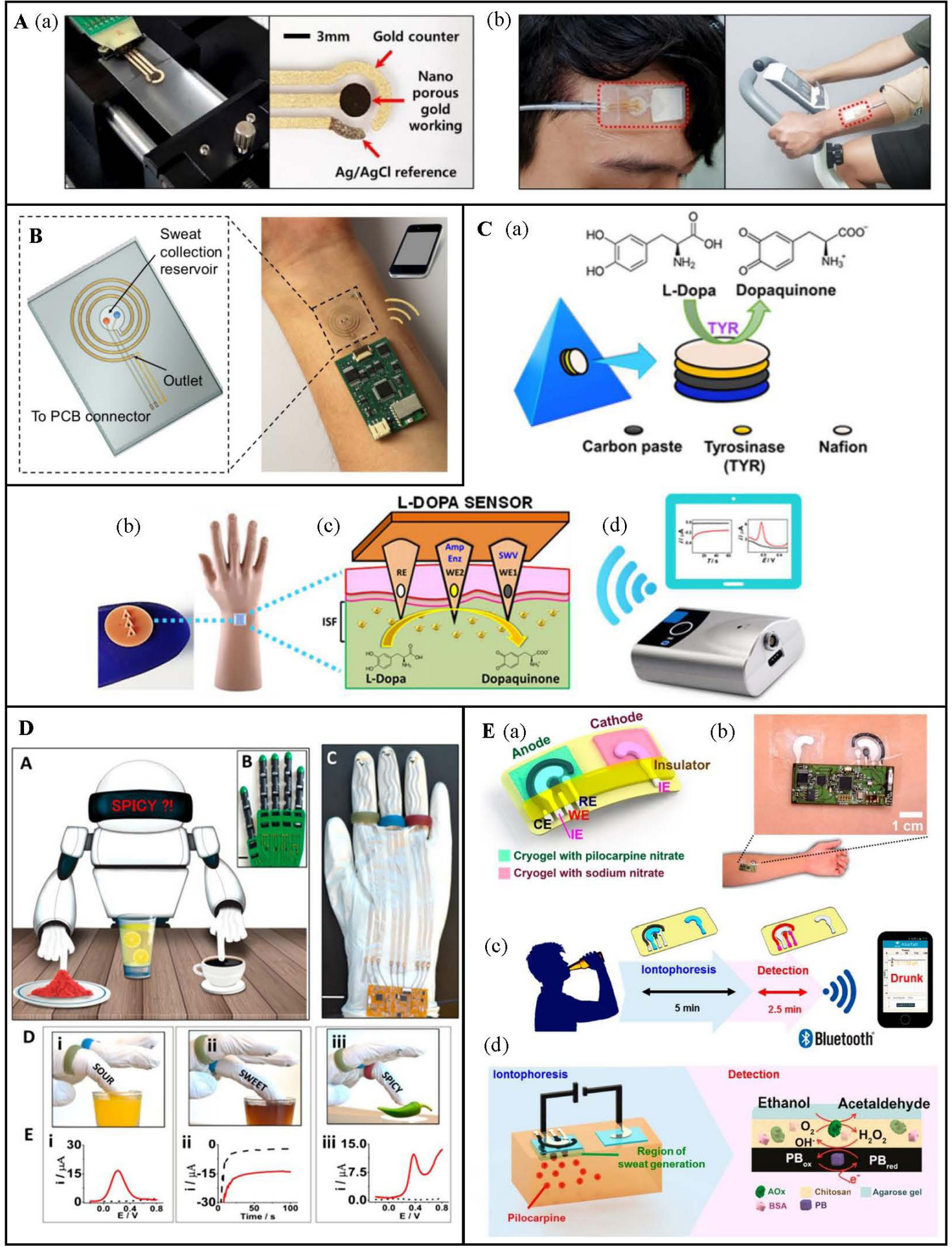

Figure 1. Example of wireless wearable electrochemical devices for different applications. A Stretchable non-enzymatic glucose wearable sensor: (a) Optical images of fabricated sensor (with no microfluidic channel); (b) Optical images of the stretchable microfluidics-integrated biosensor patch attached on the forehead (left) or arm (right) of a subject for real-time measurement. [Reprinted with permission from [65] Copyright ${ }^{\odot}$ 2019, American Chemical Society]. B - Schematics of the wearable sweat sensing patch for $\mathrm{H}^{+}, \mathrm{Na}^{+}, \mathrm{K}^{+}, \mathrm{Cl}^{-}$monitoring and sweat rate determination. The sweat sensing device is directly placed to the skin and can be comfortably worn on a user's wrist. The analyzed data is wirelessly transmitted to a cellphone via Bluetooth platform. [Reprinted 
with permission from [142] Copyright ${ }^{\odot}$ 2018, American Chemical Society]. C - Microneedle sensor for L-Dopa detection for Parkinson's disease monitoring. (a) microneedle sensor with the corresponding reagent layers, including the CP, tyrosinase, and Nafion layer; (b) Schematic representation of a mannequin hand wearing the microneedle sensor; (c) the microneedle sensor for L-Dopa monitoring in ISF; (c) Portable wireless electro analyzer enabled with wireless data transmission to a smart device. [Reprinted with permission from [148] Copyright ${ }^{\oplus}$ 2019, American Chemical Society]. D - Schematics of robotic fingers: (b) Image illustrating the robotic hand used to develop the glove-based sense fingers. (c) Prototype of the screen-printed robotic sense fingers with long connections to the wrist where the electronic interface is located. (d) Images and corresponding electrochemical data of (i) robotic sour-finger dipped in orange juice and the SWV signature of ascorbic acid, (ii) robotic sweet-finger in cherry juice and amperometry data of glucose, (iii) spicy-finger on green-pepper and SWV feedback response to the presence of capsaicin. [Reprinted with permission from [153] Copyright ${ }^{\circ}$ 2018, American Chemical Society]. E - Tattoobased transdermal alcohol sensor. (a) Schematic diagram of an iontophoretic-sensing tattoo device, containing the iontophoretic electrodes and the three sensing electrodes. (b) Photograph of an alcohol iontophoretic-sensing tattoo device with integrated flexible electronics applied to a human subject. (c) Schematic diagram of a wireless operation of the iontophoretic-sensing tattoo device for transdermal alcohol sensing. In the diagrams of the tattoo-base device, blue and red highlights show the active zones during iontophoresis and amperometric detection, respectively. (d) Schematic diagram of constituents in the iontophoretic system (left) and of the reagent layer and processes involved in the amperometric sensing of ethanol on the working electrode (right). [Reprinted with permission from [40] Copyright ${ }^{\oplus}$ 2016, American Chemical Society].

Bacteria are already well known for causing numerous diseases and disorders in the human body, such as urinary tract infection, diarrhoea, and sepsis. A real-time monitoring device is an opportunity for a direct tracking for possible bacteria contamination and infection. So, Mannoor and co-authors have developed a wireless graphene nanosensor, using biomaterials to remotely detect and monitor bacteria present in breathing or saliva. The fully integrated biosensing platform was fabricated with graphene printing onto water-soluble silk substrate, followed by functionalization of antimicrobial peptides (AMPs) as biorecognition moieties. The selective binding of the bacteria with the AMPs alters the electrical resistance and allows rapid bacterial quantification and monitoring. Upon recognition of specific bacterial targets by the immobilized peptides, the electrical conductivity of the graphene film was modulated and wirelessly monitored using an inductively coupled radio frequency (RF) reader device. The developed sensor was used in an integrated system in tooth enamel for bacteria detection in saliva and represented a versatile approach for detection of other biochemical targets using a fully wearable device [149].

Even considering that dehydration does not have specific biomarkers for its diagnosis, the monitoring of some biofluids by wearable devices has been shown to be efficient in the monitoring of people affected by this disease. The use of these wearable devices is even more important for monitoring the body condition of high-level athletes and sports practitioners, serving as an essential platform for real-time detection of water loss due to excessive physical activity. Bioelectrical impedance is the most popular and conventionally used technique for measuring dehydration and human body water content.

It consists of two electrodes mounted on the human body with a low amplitude alternating current passed through them. Frequent modifications are done to the bioelectric impedance model based on the placement of electrodes on the human body or based on putting conductive strips in wearable media, along with data readout through wireless communications, with a ZigBee-based mobile wireless sensor network [150]. Further improvements in incorporating sensors on conformable materials, especially on textiles, are also expected, enabling the wearability of such devices more efficiently for real-time analysis during exercises [151]. Wireless epidermis sensors mounted directly on human skin represent another interesting approach for measuring hydration and strain levels in the human skin for sport and fitness proposes [152]. 


\section{Wireless wearable electrochemical sensors for other applications}

As demonstrated above, many efforts have been directed towards the development of wireless wearable electrochemical devices to directly sense different biomarkers (metabolites, electrolytes). While the majority of these wearable sensor systems has focused on fitness and healthcare applications, there are growing demands for developing such sensors in various other research and industrial fields, such as security, environmental and food quality, and towards monitoring of drug abuse [154].

In particular, there is a limited number of studies describing wireless wearable electrochemical devices addressed to these other fields of applications. Wang's research Group is the pioneer in the development of fully integrated electrochemical wearable platforms with wireless data transmission for screening of food and additives flavors, monitoring hazardous chemicals for diverse security and environmental applications and drug controlling.

In the food field, Wang's group described a sensing robotic fingers device for rapid screening of food flavors and additives [153]. The device consisted of three stretchable finger electrochemical cells printed on the robotic glove, and it was integrated with a circuit board to transmit the data wirelessly, via Bluetooth to a laptop or tablet. The printed middle, index, and ring robotic fingers allowed accurate discrimination among sweetness, sourness, and spiciness, using electrochemical detection of glucose, ascorbic acid, and capsaicin in a wide range of liquid and solid food samples as can be seen in (Figure 1D). The researchers hope that these advanced wearable taste-sensing systems at the robot fingertips will pave the way to automated chemical sensing machinery, facilitating robotic decision for practical food assistance applications, with broad implications to a wide range of robotic sensing applications.

For protection and personal safety of high-risk professions, which can be exposed to toxic and hazardous species, wearable sensors fully integrated with wireless data transmission represents a very promising technology. The advantage of this technology is the integration of sensors in the clothes that are worn on a daily basis, providing the ability to continuously monitor the users and their environment to warn of an imminent risk, helping in fast and effective decision-making process [155]. Few wearable devices for detecting chemical threats have been described in the literature. Most of them are based on the detection of organophosphate (OP) nerve agents. Such compounds represent a serious concern worldwide, due to their high toxicity. Some types of OP compounds are routinely used as pesticides in agricultural and domestic environments; however, the main concern revolves around OPs such as the G series agents, sarin and soman, as they are extremely toxic and fast-acting agents of war due to its irreversible inhibition of acetylcholinesterase [156].

Wang's research group has developed promising wearable devices based on platforms such as glove [15], tattoo [157,158] and textile [158] for detecting OP compounds. Such devices consist of electrochemical sensors coupled to a miniaturized electronic interface based on a potentiostat for signal processing and wireless data transmission, via Bluetooth. In all of these systems the detection of OP compounds was based on an organophosphate hydrolase enzyme biosensor, where the OP hydrolysis product ( $p$-nitrophenol) is subsequently oxidized at the working electrode. In these studies, important points were considered. For instance, the authors used elastomeric stress-enduring inks for printing the electrodes, which ensure resilience against mechanical stress expected from the wearer's activity without compromising the biosensing performance. Moreover, the electrochemical detection was carried out using a soft and flexible electronic board, that maintains its functionality under mechanical stress and retains conformal contact with the skin.

The use of wireless wearable electrochemical devices has been also studied for the continuous realtime monitoring of licit and illicit drugs, because it plays an important role in personal and automotive safety, as well as for forensic applications [159]. Consequently, new noninvasive/few-invasive wearable chemical detection platforms, operating on readily sampled biofluids, such as sweat, saliva or tears, have attracted considerable interest as an alternative for monitoring alcohol or drugs in real time, which can be easily used by police, health workers and individual consumers. 
Thus, several wireless wearables electrochemical devices have been developed for this purpose. An interesting example is the wearable tattoo-based biosensor for noninvasive alcohol monitoring in induced sweat developed by Kim and collaborators [40]. The device is formed by an integrated system for sweatinducing direct iontophoresis with amperometric enzyme biosensing, along with a thin flexible printed electronic circuit for controlling the entire operation and a wireless real-time data collection, Figure 1E. The on-body iontophoresis operation was optimized on the human skin and the epidermal sensor was tested in nine volunteers before and after consumption of alcoholic beverages. In all experiments, the tattoo biosensors were placed on the subject's arms, and ethanol sweat measurement was performed using the iontophoresis-amperometry operation. The proposed skin-compliant biosensor displayed a highly selective and sensitive response to ethanol. The authors consider that future studies are required to calibrate the devices and ensuring data security and privacy safeguards. In addition, they point out that the attractive design and performance of the new wearable iontophoresis detection platform also offers considerable promise for noninvasive monitoring of additional target analytes.

In general, studies have pointed out the consumption of alcoholic beverages as one of the main factors responsible for the high incidence of accidents with victims. Furthermore, alcohol consumption is often combined with other psychoactive drugs, such as cannabis, and their combined synergistic effects may greatly increase the risk of fatal accidents [160]. Thus, researchers of Wang's group developed a fascinating wearable electrochemical sensing device for the simultaneous detection of salivary alcohol and $\Delta^{9}$-tetrahydrocannabinol (THC), which is the main psychoactive ingredient in cannabis [16]. The sensing platform contains a dual working electrode, which offers direct SWV detection of THC and amperometric biosensing of alcohol with no apparent cross talk and high sensitivity. Both electrochemical techniques have been executed using the potentiostatic circuit embedded within the ring body. Such ring-based integration of miniaturized wireless electronic interface facilitates selective "on the spot" detection of cannabis and alcohol. The authors point out that the proposed wearable sensing can be readily expanded for the monitoring of other drugs of abuse.

Other interesting wireless wearable electrochemical devices in these fields and its characteristics are summarized in Table I.

Although there are many challenges to be overcome for the real application and commercialization of these devices, they are fundamental to encourage the development of new improved wearable devices. 
Table I. Wireless wearable electrochemical devices for fitness, healthcare and other applications

\begin{tabular}{|c|c|c|c|c|c|c|c|}
\hline Analyte & Electrode & Linear Range & Matrix & Technique & Platform & Characteristics & Ref. \\
\hline Glucose & $\begin{array}{l}\text { GOx membrane } \\
\text { (MEMS)/Pt }\end{array}$ & $5-1000 \mu \mathrm{M}$ & Saliva & Amperometry & Mouthguard & $\begin{array}{l}\text { Long-term real-time monitoring } \\
\text { (more than } 5 \mathrm{~h} \text { ) }\end{array}$ & {$[161]$} \\
\hline Glucose & $\begin{array}{l}\text { GOx/Sol-gel } \\
\text { membrane }\end{array}$ & $0-2 \mathrm{mM}$ & Tears & Differential module & Contact Lens & $\begin{array}{l}\text { Wirelessly powered by radiated } \\
\text { RF waves }\end{array}$ & {$[162]$} \\
\hline $\mathrm{Na}^{+}$ & $\begin{array}{l}\text { Ion selective } \\
\text { membrane }\end{array}$ & - & Saliva & Potentiometry & Mouthguard & $\begin{array}{l}\text { Bluetooth low-energy wireless } \\
\text { telemetry }\end{array}$ & [163] \\
\hline $\mathbf{K}^{+}$ & $\begin{array}{l}\text { lon-selective } \\
\text { membrane/ } \\
\text { screen-printed }\end{array}$ & $0.1-100 \mathrm{mM}$ & Tears & $\begin{array}{l}\text { Amperometry and } \\
\text { Potentiometry }\end{array}$ & Eyeglass & $\begin{array}{l}\text { Nernstian slope of } 58.0 \pm 4.3 \mathrm{mV} \\
\text { Bluetooth wireless data } \\
\text { transmission }\end{array}$ & [20] \\
\hline Latic acid & $\begin{array}{l}\text { PPD-LOx/ } \\
\text { carbon-PB-printed } \\
\text { electrode }\end{array}$ & $0.1-0.5 \mathrm{mM}$ & Saliva & $\mathrm{CA}$ & Mouthguard & $\begin{array}{l}\text { High sensitivity, selectivity and } \\
\text { stability using whole human } \\
\text { saliva samples }\end{array}$ & [59] \\
\hline Latic acid & $\begin{array}{l}\text { LOx/ } \\
\text { glutaraldehyde/ } \\
\text { BSA/PU/Pt }\end{array}$ & $0-1 \mathrm{mM}$ & Tears & Amperometry & Contact lens & $\begin{array}{l}\text { Quick response time Sensitivity } \\
\text { of } \sim 53 \mathrm{~A} \mathrm{mM}^{-1}\end{array}$ & [164] \\
\hline Dehydration & AgNW/PDMS & - & - & Impedance & Skin & $\begin{array}{l}\text { Ultralow power microprocessor } \\
\text { with Bluetooth wireless } \\
\text { connection }\end{array}$ & {$[165]$} \\
\hline $\begin{array}{l}\text { Glucose, AA, caffeine } \\
\text { (CAF) and capsaicin } \\
\text { (CAP) }\end{array}$ & $\begin{array}{l}\text { Carbon-printed } \\
\text { electrode and } \\
\text { GOx/PB/carbon- } \\
\text { printed electrode }\end{array}$ & $\begin{array}{l}\text { 1-6 mM AA and } \\
\text { glucose; } \\
\text { 10-50 ppm CAP; } \\
0.1-0.9 \text { mM CAF }\end{array}$ & Food & $\begin{array}{l}\text { SWV and } \\
\text { Amperometry }\end{array}$ & Nitrile glove & $\begin{array}{l}\text { Robotic sensors that mimic the } \\
\text { human sensing capabilities } \\
\text { to discriminate sweetness, } \\
\text { sourness, and spiciness }\end{array}$ & [153] \\
\hline $\begin{array}{l}\text { Organophosphorus } \\
\text { nerve agent } \\
\text { (methylparaoxon and } \\
\text { methylparation) }\end{array}$ & $\begin{array}{l}\text { OPH/Nafion/ } \\
\text { carbon-printed } \\
\text { electrode }\end{array}$ & - & Surfaces & SWV & Nitrile glove & $\begin{array}{l}\text { "Lab-on-a-glove" that withstand } \\
\text { extreme mechanical deformations }\end{array}$ & [15] \\
\hline $\begin{array}{l}\text { G-type nerve agents } \\
\text { simulant (diisopropyl } \\
\text { fluorophosphate) }\end{array}$ & $\begin{array}{l}\text { OPH/Nafion/PANi/ } \\
\text { carbon-printed } \\
\text { electrode }\end{array}$ & $10-120 \mathrm{mM}$ & $\begin{array}{l}\text { Vapor and } \\
\text { liquid phases }\end{array}$ & Potentiometry & Tattoo & $\begin{array}{l}\text { Temporary tattoo } \\
\text { paper and miniaturized } \\
\text { potentiometric printed circuit } \\
\text { board transducer integrated }\end{array}$ & {$[157]$} \\
\hline $\begin{array}{l}\text { Organophosphorus } \\
\text { nerve agent } \\
\text { (methylparaoxon) }\end{array}$ & $\begin{array}{l}\text { OPH/Nafion/ } \\
\text { carbon-printed } \\
\text { electrode }\end{array}$ & $90-300 \mathrm{mg} \mathrm{L}^{-1}$ & Vapor phases & SWV & Tattoo and textile & $\begin{array}{l}\text { Maintains its functionality under } \\
\text { mechanical stress and retains } \\
\text { conformal contact with the skin }\end{array}$ & [158] \\
\hline $\begin{array}{l}\text { Explosive and } \\
\text { nerve-agent threats } \\
\text { (DNT, } \mathrm{H}_{2} \mathrm{O}_{2} \text { and } \\
\text { methylparaoxon) }\end{array}$ & $\begin{array}{l}\text { Carbon and } \\
\text { OPH/Nafion/ } \\
\text { carbon-PB-printed } \\
\text { electrode }\end{array}$ & $\begin{array}{l}10-100 \mathrm{ppm} \\
2-10 \mathrm{mM} \\
0.25-1.25 \mathrm{mM}\end{array}$ & $\begin{array}{l}\text { Vapor and } \\
\text { liquid phases }\end{array}$ & $\begin{array}{l}\text { SWV and } \\
\text { Amperometry }\end{array}$ & Ring & $\begin{array}{l}\text { Multiplexed chemical sensor } \\
\text { platform with battery-powered } \\
\text { stamp-size potentiostat }\end{array}$ & [13] \\
\hline
\end{tabular}


Table I. Wireless wearable electrochemical devices for fitness, healthcare and other applications (Continuation)

\begin{tabular}{|c|c|c|c|c|c|c|c|}
\hline Analyte & Electrode & Linear Range & Matrix & Technique & Platform & Characteristics & Ref. \\
\hline Ethanol & $\begin{array}{l}\text { AOx/BSA/chitosan/ } \\
\text { carbon-PB-printed } \\
\text { electrode }\end{array}$ & $0-36 \mathrm{mM}$ & Sweat & Amperometry & Tattoo & $\begin{array}{l}\text { Wireless epidermal iontophoretic- } \\
\text { biosensing system }\end{array}$ & [40] \\
\hline Ethanol & AOx/PPy/Au & $1-50 \mathrm{mM}$ & Interstitial fluid & $\begin{array}{l}\text { Amperometry and } \\
\text { potentiometry }\end{array}$ & 16-gauge syringe & $\begin{array}{l}\text { Continuous and long-term } \\
\text { monitoring }\end{array}$ & [166] \\
\hline $\begin{array}{l}\text { Ethanol, glucose and } \\
\text { vitamins }\left(C, B_{2}, B_{6}\right)\end{array}$ & $\begin{array}{l}\text { Carbon-PB-, GOx/ } \\
\text { BSA/carbon-PB- } \\
\text { and AOx/BSA/ } \\
\text { carbon-PB-printed } \\
\text { electrode }\end{array}$ & - & Tears & $\begin{array}{l}\text { SWV and } \\
\text { amperometry }\end{array}$ & Eyeglasses & $\begin{array}{l}\text { Noninvasive biosensing fluidic } \\
\text { system allow real-time tear } \\
\text { collection and direct biomarkers } \\
\text { measurements }\end{array}$ & [96] \\
\hline $\begin{array}{l}\text { Ethanol and } \Delta^{9}- \\
\text { tetrahydrocannabinol } \\
\text { (THC) }\end{array}$ & $\begin{array}{l}\text { AOx/BSA/chitosan/ } \\
\text { glutaraldehyde/ } \\
\text { carbon-PB- and } \\
\text { MWCNT/carbon- } \\
\text { printed electrode }\end{array}$ & $\begin{array}{l}0.2-1.0 \mathrm{mM} \\
\text { ethanol; } \\
1-6 \mu \mathrm{M} \text { THC }\end{array}$ & Saliva & $\begin{array}{l}\text { SWV and } \\
\text { amperometry }\end{array}$ & Ring & $\begin{array}{l}\text { Powerful wireless electronic } \\
\text { board into a ring platform; Dual- } \\
\text { sensor electrode cap, for the } \\
\text { simultaneous detection }\end{array}$ & [16] \\
\hline Drug (Caffeine) & $\begin{array}{l}\text { CNTs/Nafion/ } \\
\text { carbon printed } \\
\text { electrode }\end{array}$ & $10-40 \mu \mathrm{M}$ & Sweat & DPV & Wrist band & $\begin{array}{l}\text { Complete system with signal } \\
\text { transduction, conditioning, } \\
\text { processing, and Bluetooth } \\
\text { transmission functionalities to } \\
\text { relay electrochemical signals to a } \\
\text { user interface }\end{array}$ & [45] \\
\hline Abuse drug (fentanyl) & $\begin{array}{l}\text { MWCNT-PEI-IL/ } \\
\text { carbon printed } \\
\text { electrode }\end{array}$ & $10-100 \mu \mathrm{M}$ & $\begin{array}{l}\text { Liquid and } \\
\text { powder forms }\end{array}$ & SWV & Glove & $\begin{array}{l}\text { Selective detection in the } \\
\text { presence of common cutting } \\
\text { agents such as acetaminophen, } \\
\text { caffeine, glucose, and } \\
\text { theophylline }\end{array}$ & [167] \\
\hline
\end{tabular}

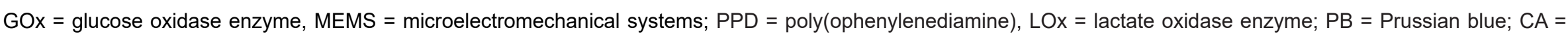

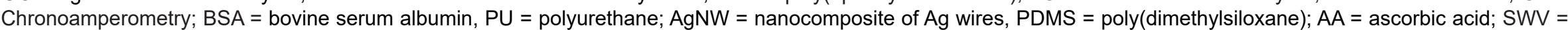

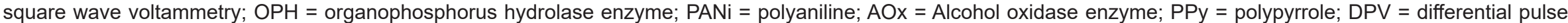
voltammetry; CNTs = carbon nanotubes; MWCNT = Multiwalled carbon nanotubes; PEI = polyethylenimine; IL = ionic liquid. 


\section{CONCLUSION AND OUTLOOK}

The area of wearable sensors is being developed in an extraordinary way. Advances in fields such as nanotechnology and the Internet-of-Things have boosted the ability of such devices to extract quantitative and innovative information in real-time, especially in remote areas and with limited resources, revolutionizing user health, well-being and safety practices.

Electroanalytical methods have received great attention in the last decade for the manufacture of these wearable platforms. This is because such methods allow the manufacture of fully integrated devices in a miniaturized, flexible and robust way, allowing the directly analysis on the human body, processing and transmitting data wirelessly to a portable device or a data center. Moreover, the functionalization of electrochemical sensors, supported on this wearable platform, with nanomaterials or bioreceptors can improve the analytical performance of the entire system, improving its sensitivity, selectivity and versatility.

Most of the developments in wearable sensors has been focused on health/fitness applications, however, these devices are extremely important for various scientific and industrial fields. Recent efforts have demonstrated its potential for in field monitoring that are still little explored, such as security and defense, agri-food and forensic applications.

Although there are unquestionable advantages in using wireless wearable electrochemical devices, most of the works described in this review have as their main objective the manufacture of the devices, demonstrating only the potential of the proposed devices. Little attention has been paid to critical and fundamental steps towards the final purpose of the device from the point of view of real applications and commercialization.

Importantly, the impact of this technology is still at an early stage. As with most new developments, there are many challenges and opportunities for this relatively new field, both in fundamental and applied aspects. These challenges involve the improvement of sensitivity, selectivity, long-term stability and reliability of devices and multiplexing capabilities. More researches are needed to manufacture largescale wireless wearable electrochemical sensors with reliable performance for relevant analytes in real samples and viable scenarios, in order to make it the best option to solve real demand. The improvement of the multidisciplinary synergy of chemistry, biology, electrical engineering and software engineering will play a central role in the creation of innovative portable and wireless wearable microdevices with excellent performance.

\section{Acknowledgements}

The authors gratefully acknowledge the financial support from the Brazilian funding agencies São Paulo Research Foundation (FAPESP: grant numbers 2013/22127-2 and 2019/00166), National Council for Scientific and Technological Development (CNPq Grant no. 136386/2019-9), CAPES and National Institute of Science \& Technology in Bioanalytics (INCTBio).

This work is dedicated to our friend Gustavo Arantes Lorga, who left us so early! The four loves of his life were: God, family, friends and science. Unfortunately, science became orphaned by a great and dedicated researcher, disposed to make relevant contributions to the scientific community. Gustavo was involved with great affection for each of the members of his research group, showing special appreciation for Prof. Lauro Tatsuo Kubota, whom he greatly admired. We are grateful for all the time by your side, Gustavo!

\section{REFERENCES}

1. Atzori, L.; lera, A.; Morabito, G. Comput. Networks, 2010, 54, pp 2787-2805 (https://doi.org/10.1016/j. comnet.2010.05.010).

2. Kassal, P.; Steinberg, M. D.; Steinberg, I. M. Sens. Actuators, B, 2018, 266, pp 228-245 (https://doi. org/10.1016/j.snb.2018.03.074).

3. Tan, L.; Wang, N. IEEE, 2010, pp V5-376-V375-380 (https://doi.org/10.1109/ICACTE.2010.5579543).

4. Bonastre, A.; Capella, J. V.; Ors, R.; Peris, M. TrAC, Trends Anal. Chem., 2012, 34, pp 111-125 (https://doi.org/10.1016/j.trac.2011.11.009). 
5. Feng, X.; Yan, F.; Liu, X., Wirel. Pers. Commun., 2019, 108, pp 1785-1802 (https://doi.org/10.1007/ s11277-019-06496-7).

6. Rateni, G.; Dario, P.; Cavallo, F. Sensors, 2017, 17, p 1453 (https://doi.org/10.3390/s17061453).

7. Windmiller, J. R.; Wang, J. Electroanalysis, 2013, 25, pp 29-46 (https://doi.org/10.1002/ elan.201200349).

8. Steinberg, M. D.; Kassal, P.; Steinberg, I. M. Electroanalysis, 2016, 28, pp 1149-1169 (https://doi. org/10.1002/elan.201600094).

9. Guk, K.; Han, G.; Lim, J.; Jeong, K.; Kang, T.; Lim, E.-K.; Jung, J. Nanomaterials, 2019, 9, p 813 (https://doi.org/10.3390/nano9060813).

10. Tricoli, A.; Nasiri, N.; De, S. Adv. Funct. Mater., 2017, 27, p 1605271 (https://doi.org/10.1002/ adfm.201605271).

11. Xu, K.; Lu, Y.; Takei, K. Adv. Mater. Technol., 2019, 4, p 1800628 (https://doi.org/10.1002/ admt.201800628).

12. Bariya, M.; Nyein, H. Y. Y.; Javey, A. Nat. Electron., 2018, 1, pp 160-171 (https://doi.org/10.1038/ s41928-018-0043-y).

13. Sempionatto, J. R.; Mishra, R. K.; Martín, A.; Tang, G.; Nakagawa, T.; Lu, X.; Campbell, A.S.; Lyu, K. M.; Wang, J. ACS Sens., 2017, 2, pp 1531-1538 (https://doi.org/10.1021/acssensors.7b00603).

14. Seesaard, T.; Lorwongtragool, P.; Kerdcharoen, T. J. S. Sensors, 2015, 15, pp 1885-1902 (https:// doi.org/10.3390/s150101885).

15. Mishra, R. K.; Hubble, L. J.; Martín, A.; Kumar, R.; Barfidokht, A.; Kim, J.; Musameh, M. M.; Kyratzis, I. L.; Wang, J. ACS Sens., 2017, 2, pp 553-561 (https://doi.org/10.1021/acssensors.7b00051).

16. Mishra, R. K.; Sempionatto, J. R.; Li, Z.; Brown, C.; Galdino, N. M.; Shah, R.; Liu, S.; Hubble, L. J.; Bagot, K.; Tapert, S.; et al., Talanta, 2020, 211, p 120757 (https://doi.org/10.1016/j.talanta.2020.120757).

17. Lin, S.; Wang, B.; Yu, W.; Castillo, K.; Hoffman, C.; Cheng, X.; Zhao, Y.; Gao, Y.; Wang, Z.; Lin, H.; et al. ACS Sens., 2020, 5, pp 265-273 (https://doi.org/10.1021/acssensors.9b02233).

18. de Jong, M.; Sleegers, N.; Kim, J.; Van Durme, F.; Samyn, N.; Wang, J.; De Wael, K. Chem. Sci., 2016, 7, pp 2364-2370 (https://doi.org/10.1039/C5SC04309C).

19. Malzahn, K.; Windmiller, J. R.; Valdés-Ramírez, G.; Schöning, M. J.; Wang, J. Analyst, 2011, 136, pp 2912-2917 (https://doi.org/10.1039/C1AN15193B).

20. Sempionatto, J. R.; Nakagawa, T.; Pavinatto, A.; Mensah, S. T.; Imani, S.; Mercier, P.; Wang, J. Lab on a Chip, 2017, 17, pp 1834-1842 (https://doi.org/10.1039/c7lc00192d).

21. Martín, A.; Kim, J.; Kurniawan, J. F.; Sempionatto, J. R.; Moreto, J. R.; Tang, G.; Campbell, A. S.; Shin, A.; Lee, M. Y.; Liu, X.; et al., ACS Sens., 2017, 2, pp 1860-1868 (https://doi.org/10.1021/ acssensors.7b00729).

22. Kim, J.; Imani, S.; de Araujo, W. R.; Warchall, J.; Valdés-Ramírez, G.; Paixão, T. R. L. C.; Mercier, P. P.; Wang, J. Biosens. Bioelectron., 2015, 74, pp 1061-1068 (https://doi.org/10.1016/j.bios.2015.07.039).

23. Mak, W. C.; Cheung, K. Y.; Orban, J.; Lee, C.-J.; Turner, A. P. F.; Griffith, M. ACS Appl. Mater. Interfaces, 2015, 7, pp 25487-25494 (https://doi.org/10.1021/acsami.5b08644).

24. Koh, A.; Kang, D.; Xue, Y.; Lee, S.; Pielak, R. M.; Kim, J.; Hwang, T.; Min, S.; Banks, A.; Bastien, P.; et al. Sci. Transl. Med., 2016, 8, pp 366ra165-366ra165 (https://doi.org/10.1126/scitranslmed. aaf2593).

25. Kim, J.; Campbell, A. S.; de Ávila, B. E.-F.; Wang, J. Nat. Biotechnol., 2019, 37, pp 389-406 (https:// doi.org/10.1038/s41587-019-0045-y).

26. Mayer, M.; Baeumner, A. J. Chem. Rev., 2019, 119, pp 7996-8027 (https://doi.org/10.1021/acs. chemrev.8b00719).

27. Teymourian, H.; Parrilla, M.; Sempionatto, J. R.; Montiel, N. F.; Barfidokht, A.; Van Echelpoel, R.; De Wael, K.; Wang, J. ACS Sensors, 2020, 5, pp 2679-2700 (https://doi.org/10.1021/ acssensors.0c01318).

28. Sekar, M.; Sriramprabha, R.; Sekhar, P. K.; Bhansali, S.; Ponpandian, N.; Pandiaraj, M.; Viswanathan, C. J. Electrochem. Soc., 2020, 167, p 067508 (https://doi.org/10.1149/1945-7111/ab7e24). 
29. Kassal, P.; Horak, E.; Sigurnjak, M.; Steinberg, M. D.; Steinberg, I. M. Rev. Anal. Chem., 2018, 37 (https://doi.org/10.1515/revac-2017-0024).

30. https://www.idtechex.com/en/research-report/wearable-technology-forecasts-2019-2029/2680 [accessed 2 October 2020].

31. Steinberg, M. D.; Kassal, P.; Kereković, I.; Steinberg, I. M. Talanta, 2015, 143, pp 178-183 (https:// doi.org/10.1016/j.talanta.2015.05.028).

32. Bandodkar, A. J.; Jeerapan, I.; Wang, J. ACS Sens., 2016, 1, pp 464-482 (https://doi.org/10.1021/ acssensors.6b00250).

33. Yang, X.; Cheng, H. Micromachines, 2020, 11, p 243 (https://doi.org/10.3390/mi11030243).

34. Gao, W.; Emaminejad, S.; Nyein, H. Y. Y.; Challa, S.; Chen, K.; Peck, A.; Fahad, H. M.; Ota, H.; Shiraki, H.; Kiriya, D.; et al. Nature, 2016, 529, pp 509-514 (https://doi.org/10.1038/nature16521).

35. Choi, J.; Ghaffari, R.; Baker, L. B.; Rogers, J. A. Sci. Adv., 2018, 4, p eaar3921 (https://doi.org/10.1126/ sciadv.aar3921).

36. Kim, S. B.; Koo, J.; Yoon, J.; Hourlier-Fargette, A.; Lee, B.; Chen, S.; Jo, S.; Choi, J.; Oh, Y. S.; Lee, G.; et al. Lab on a Chip, 2020, 20, pp 84-92 (https://doi.org/10.1039/C9LC01045A).

37. Nyein, H. Y. Y.; Gao, W.; Shahpar, Z.; Emaminejad, S.; Challa, S.; Chen, K.; Fahad, H. M.; Tai, L.-C.; Ota, H.; Davis, R. W.; et al. ACS Nano, 2016, 10, pp 7216-7224 (https://doi.org/10.1021/ acsnano.6b04005).

38. Salim, A.; Lim, S. Biosens Bioelectron, 2019, 141, p 111422 (https://doi.org/10.1016/j. bios.2019.111422).

39. Bandodkar, A. J.; Jia, W.; Yardımcı, C.; Wang, X.; Ramirez, J.; Wang, J. Anal. Chem., 2015, 87, pp 394-398 (https://doi.org/10.1021/ac504300n).

40. Kim, J.; Jeerapan, I.; Imani, S.; Cho, T. N.; Bandodkar, A.; Cinti, S.; Mercier, P. P.; Wang, J. ACS Sens., 2016, 1, pp 1011-1019 (https://doi.org/10.1021/acssensors.6b00356).

41. Gao, W.; Nyein, H. Y. Y.; Shahpar, Z.; Fahad, H. M.; Chen, K.; Emaminejad, S.; Gao, Y.; Tai, L.-C.; Ota, H.; Wu, E.; et al. ACS Sens., 2016, 1, pp 866-874 (https://doi.org/10.1021/acssensors.6b00287).

42. Windmiller, J. R.; Bandodkar, A. J.; Valdés-Ramírez, G.; Parkhomovsky, S.; Martinez, A. G.; Wang, J. Chem. Commun., 2012, 48, pp 6794-6796 (https://doi.org/10.1039/C2CC32839A).

43. Wang, B.; Wilhelm, A.; Wilhelm, A.; Pilehvar, S.; Moshfeghi, S.; Stout, P.; Salahi, K.; Emaminejad, S. - Wearable Chemical Sensors. In: Parlak, O.; Salleo, A.; Turner, A. (Eds.) Wearable Bioelectronics, Elsevier, 2020, Chapter 2 (https://doi.org/10.1016/B978-0-08-102407-2.00003-5).

44. Baeg, K.-J.; Lee, J. Adv. Mater. Technol., 2020, 5, p 2000071 (https://doi.org/10.1002/ admt.202000071).

45. Tai, L.-C.; Gao, W.; Chao, M.; Bariya, M.; Ngo, Q. P.; Shahpar, Z.; Nyein, H. Y. Y.; Park, H.; Sun, J.; Jung, Y.; et al. Adv. Mater., 2018, 30, p. 1707442 (https://doi.org/10.1002/adma.201707442).

46. Manjakkal, L.; Dang, W.; Yogeswaran, N.; Dahiya, R. J. B. Biosensors, 2019, 9, p 14 (https://doi. org/10.3390/bios9010014).

47. Keum, D. H.; Kim, S.-K.; Koo, J.; Lee, G.-H.; Jeon, C.; Mok, J. W.; Mun, B. H.; Lee, K. J.; Kamrani, E.; Joo, C.-K.; et al. Sci. Adv., 2020, 6, p eaba3252 (https://doi.org/10.1126/sciadv.aba3252).

48. Cass, A. E.; Sharma, S. Methods Enzymol., 2017, 589, pp 413-427 (https://doi.org/10.1016/ bs.mie.2017.02.002).

49. Indrakumari, R.; Poongodi, T.; Suresh, P.; Balamurugan, B. The Growing Role of Internet of Things in Healthcare Wearables. In: Balas, V. E.; Solanki, V. K.; Kumar, R. (Eds.) Emergence of Pharmaceutical Industry Growth with Industrial lot Approach. Academic Press, 2020, Chapter 6 (https://doi.org/10.1016/B978-0-12-819593-2.00006-6).

50. Yu, Y.; Nyein, H. Y. Y.; Gao, W.; Javey, A. Adv. Mater., 2020, 32, p 1902083 (https://doi.org/10.1002/ adma.201902083).

51. Matzeu, G.; Florea, L.; Diamond, D. Sens. Actuators, B, 2015, 211, pp 403-418 (https://doi. org/10.1016/j.snb.2015.01.077). 
52. Miller, P. R.; Skoog, S. A.; Edwards, T. L.; Lopez, D. M.; Wheeler, D. R.; Arango, D. C.; Xiao, X.; Brozik, S. M.; Wang, J.; Polsky, R.; et al. Talanta, 2012, 88, pp 739-742 (https://doi.org/10.1016/j. talanta.2011.11.046).

53. Mohan, A. M. V.; Windmiller, J. R.; Mishra, R. K.; Wang, J. Biosens Bioelectron, 2017, 91, pp 574579 (https://doi.org/10.1016/j.bios.2017.01.016).

54. Bandodkar, A. J.; Wang, J. Trends Biotechnol., 2014, 32, pp 363-371 (https://doi.org/10.1016/j. tibtech.2014.04.005).

55. Dei, M.; Aymerich, J.; Piotto, M.; Bruschi, P.; del Campo, F. J.; Serra-Graells, F. Electronics, 2019, 8, p 150 (https://doi.org/10.3390/electronics8020150).

56. Sieg, A.; Guy, R. H.; Begoña Delgado-Charro, M. Biophys. J., 2004, 87, pp 3344-3350 (https://doi. org/10.1529/biophysj.104.044792).

57. Leboulanger, B.; Guy, R. H.; Delgado-Charro, M. B. Physiol. Meas., 2004, 25, pp R35-R50 (https:// doi.org/10.1088/0967-3334/25/3/r01).

58. Varadharaj, E. K.; Jampana, N. J. Electrochem. Soc., 2016, 163, pp B340-B347 (https://doi. org/10.1149/2.0751607jes).

59. Kim, J.; Valdés-Ramírez, G.; Bandodkar, A. J.; Jia, W.; Martinez, A. G.; Ramírez, J.; Mercier, P.; Wang, J. Analyst, 2014, 139, pp 1632-1636 (https://doi.org/10.1039/c3an02359a).

60. Leboulanger, B.; Aubry, J.-M.; Bondolfi, G.; Guy, R. H.; Delgado-Charro, M. B. Clin. Chem., 2004, 50, pp 2091-2100 (https://doi.org/10.1373/clinchem.2004.034249).

61. Qiao, L.; Benzigar, M. R.; Subramony, J. A.; Lovell, N. H.; Liu, G. ACS Appl. Mater. Interfaces, 2020, 12, pp 34337-34361 (https://doi.org/10.1021/acsami.0c07614).

62. Jia, W.; Bandodkar, A. J.; Valdés-Ramírez, G.; Windmiller, J. R.; Yang, Z.; Ramírez, J.; Chan, G.; Wang, J. Anal. Chem., 2013, 85, pp 6553-6560 (https://doi.org/10.1021/ac401573r).

63. Heikenfeld, J. Electroanalysis, 2016, 28, pp 1242-1249 (https://doi.org/10.1002/elan.201600018).

64. Salim, A.; Lim, S. Biosens. Bioelectron., 2019, 141, p 111422 (https://doi.org/10.1016/j. bios.2019.111422).

65. Bae, C. W.; Toi, P. T.; Kim, B. Y.; Lee, W. I.; Lee, H. B.; Hanif, A.; Lee, E. H.; Lee, N.-E. ACS Appl. Mater. Interfaces, 2019, 11, pp 14567-14575 (https://doi.org/10.1021/acsami.9b00848).

66. Lou, Z.; Wang, L.; Jiang, K.; Wei, Z.; Shen, G. Mater. Sci. Eng. R Rep., 2020, 140, p 100523 (https:// doi.org/10.1016/j.mser.2019.100523).

67. Zhao, Y.; Huang, X. J. M. Micromachines, 2017, 8, p 69 (https://dx.doi.org/10.3390\%2Fmi8030069).

68. Jin, X.; Liu, C.; Xu, T.; Su, L.; Zhang, X. Biosens. Bioelectron., 2020, 165, p 112412 (https://doi. org/10.1016/j.bios.2020.112412).

69. Deroco, P. B.; Giarola, J. F.; Wachholz Júnior, D.; Arantes, G. L.; Kubota, L. T. Paper-Based Electrochemical Sensing Devices. In: Merkoçi, A. (Ed.) Comprehensive Analytical Chemistry, Elsevier, 2020, Chapter 4 (https://doi.org/10.1016/bs.coac.2019.11.001).

70. Ferreira, P. C.; Ataíde, V. N.; Silva Chagas, C. L.; Angnes, L.; Tomazelli Coltro, W. K.; Longo Cesar Paixão, T. R.; Reis de Araujo, W. TrAC, Trends Anal. Chem., 2019, 119, p 115622 (https://doi. org/10.1016/j.trac.2019.115622).

71. Paracha, K. N.; Rahim, S. K. A.; Soh, P. J.; Khalily, M. J. I. A. IEEE Access, 2019, 7, pp 56694-56712 (https://doi.org/10.1109/ACCESS.2019.2909146).

72. Zhao, S.; Li, J.; Cao, D.; Zhang, G.; Li, J.; Li, K.; Yang, Y.; Wang, W.; Jin, Y.; Sun, R.; et al. ACS Appl. Mater. Interfaces, 2017, 9, pp 12147-12164 (https://doi.org/10.1021/acsami.6b13800).

73. Lee, J.; Llerena Zambrano, B.; Woo, J.; Yoon, K.; Lee, T. Adv. Mater., 2020, 32, p 1902532 (https:// doi.org/10.1002/adma.201902532).

74. Liu, Q.; Zhang, M.; Huang, L.; Li, Y.; Chen, J.; Li, C.; Shi, G. ACS Nano, 2015, 9, pp 12320-12326 (https://doi.org/10.1021/acsnano.5b05609).

75. Akter, T.; Kim, W. S. ACS Appl. Mater. Interfaces, 2012, 4, pp 1855-1859 (https://doi.org/10.1021/ am300058j). 
76. Cronholm, P.; Karlsson, H. L.; Hedberg, J.; Lowe, T. A.; Winnberg, L.; Elihn, K.; Wallinder, I. O.; Möller, L. Small, 2013, 9, pp 970-982 (https://doi.org/10.1002/smll.201201069).

77. Kim, J.; Kumar, R.; Bandodkar, A. J.; Wang, J. Adv. Electron. Mater., 2017, 3, p 1600260 (https://doi. org/10.1002/aelm.201600260).

78. Søpstad, S.; Johannessen, E. A.; Imenes, K. Results Chem., 2020, 2, p 100028 (https://doi. org/10.1016/j.rechem.2020.100028).

79. Shinwari, M. W.; Zhitomirsky, D.; Deen, I. A.; Selvaganapathy, P. R.; Deen, M. J.; Landheer, D. Sensors (Basel, Switzerland), 2010, 10, pp 1679-1715 (https://doi.org/10.3390/s100301679).

80. Sophocleous, M.; Atkinson, J. K. Sens. Actuators, A, 2017, 267, pp 106-120 (https://doi.org/10.1016/j. sna.2017.10.013).

81. Khan, S.; Ali, S.; Bermak, A. Sensors, 2019, 19, p 1230 (https://dx.doi.org/10.3390\%2Fs19051230).

82. Bandodkar, A. J.; Gutruf, P.; Choi, J.; Lee, K.; Sekine, Y.; Reeder, J. T.; Jeang, W. J.; Aranyosi, A. J.; Lee, S. P.; Model, J. B.; et al. Sci. Adv., 2019, 5, p eaav3294 (https://doi.org/10.1126/sciadv. aav3294).

83. Picher, M. M.; Küpcü, S.; Huang, C. J.; Dostalek, J.; Pum, D.; Sleytr, U. B.; Ertl, P. Lab on a Chip, 2013, 13, pp 1780-1789 (https://doi.org/10.1039/c3lc41308j).

84. Moussy, F.; Harrison, D. J.; Rajotte, R. V. Int. J. Artif. Organs., 1994, 17, pp 88-94.

85. Prime, K.; Whitesides, G. Science, 1991, 252, pp 1164-1167 (https://doi.org/10.1126/ science.252.5009.1164).

86. Banerjee, I.; Pangule, R. C.; Kane, R. S. Adv. Mater., 2011, 23, pp 690-718 (https://doi.org/10.1002/ adma.201001215).

87. Matos-Pérez, C. R.; Wilker, J. J. Macromolecules, 2012, 45, pp 6634-6639 (https://doi.org/10.1021/ ma300962d).

88. Ding, X.; Yang, C.; Lim, T. P.; Hsu, L. Y.; Engler, A. C.; Hedrick, J. L.; Yang, Y.-Y. Biomaterials, 2012, 33, pp 6593-6603 (https://doi.org/10.1016/j.biomaterials.2012.06.001).

89. Mi, L.; Jiang, S. Angew. Chem. Int. Ed., 2014, 53, pp 1746-1754 (https://doi.org/10.1002/ anie.201304060).

90. Chang, Y.; Shih, Y.-J.; Lai, C.-J.; Kung, H.-H.; Jiang, S. Adv. Funct. Mater., 2013, 23, pp 1100-1110 (https://doi.org/10.1002/adfm.201201386).

91. Fritzsche, E.; Staudinger, C.; Fischer, J. P.; Thar, R.; Jannasch, H. W.; Plant, J. N.; Blum, M.; Massion, G.; Thomas, H.; Hoech, J.; et al. Mar. Chem., 2018, 207, pp 63-76 (https://doi.org/10.1016/j. marchem.2018.10.009).

92. Pifferi, V.; Soliveri, G.; Panzarasa, G.; Ardizzone, S.; Cappelletti, G.; Meroni, D.; Falciola, L. RSC Adv., 2015, 5, pp 71210-71214 (https://doi.org/10.1039/C5RA12219H).

93. Yan, M.; Ribeiro, R. M. Chemically Robust Miniature Gas Sensors. Us Patent Application 20190025271 ', 2019.

94. Rocklin, R. D.; Clarke, A. P.; Weitzhandler, M. Anal. Chem., 1998, 70, pp 1496-1501 (https://doi. org/10.1021/ac970906w).

95. Laborda, E.; González, J.; Molina, Á. Electrochem. Commun., 2014, 43, pp 25-30 (https://doi. org/10.1016/j.elecom.2014.03.004).

96. Sempionatto, J. R.; Brazaca, L. C.; García-Carmona, L.; Bolat, G.; Campbell, A. S.; Martin, A.; Tang, G.; Shah, R.; Mishra, R. K.; Kim, J.; et al. Biosens. Bioelectron., 2019, 137, pp 161-170 (https://doi. org/10.1016/j.bios.2019.04.058).

97. Rose, D. P.; Ratterman, M. E.; Griffin, D. K.; Hou, L.; Kelley-Loughnane, N.; Naik, R. R.; Hagen, J. A.; Papautsky, I.; Heikenfeld, J. C. IEEE. Trans. Biomed. Eng., 2015, 62, pp 1457-1465 (https://doi. org/10.1109/TBME.2014.2369991).

98. Caldara, M.; Colleoni, C.; Guido, E.; Re, V.; Rosace, G. Sens. Actuators, B, 2016, 222, pp 213-220 (https://doi.org/10.1016/j.snb.2015.08.073). 
99. Liu, G.; Ho, C.; Slappey, N.; Zhou, Z.; Snelgrove, S. E.; Brown, M.; Grabinski, A.; Guo, X.; Chen, Y.; Miller, K.; et al. Sens. Actuators, B, 2016, 227, pp 35-42 (https://doi.org/10.1016/j.snb.2015.12.034).

100. Xiao, Z.; Tan, X.; Chen, X.; Chen, S.; Zhang, Z.; Zhang, H.; Wang, J.; Huang, Y.; Zhang, P.; Zheng, L.; et al. IEEE J. Biomed. Health Inform., 2015, 19, pp 910-919 (https://doi.org/10.1109/ JBHI.2015.2415836).

101. Jung, Y.; Park, H.; Park, J.-A.; Noh, J.; Choi, Y.; Jung, M.; Jung, K.; Pyo, M.; Chen, K.; Javey, A.; et al. Sci. Rep., 2015, 5, p 8105 (https://doi.org/10.1038/srep08105).

102. Kassal, P.; Kim, J.; Kumar, R.; de Araujo, W. R.; Steinberg, I. M.; Steinberg, M. D.; Wang, J., Electrochem. Commun., 2015, 56, pp 6-10 (https://doi.org/10.1016/j.elecom.2015.03.018).

103. Lazaro, A.; Boada, M.; Villarino, R.; Girbau, D., Sensors, 2019, 19, p 1741 (https://doi.org/10.3390/ s19071741)

104. Zamarayeva, A. M.; Ostfeld, A. E.; Wang, M.; Duey, J. K.; Deckman, I.; Lechêne, B. P.; Davies, G.; Steingart, D. A.; Arias, A. C. Sci. Adv., 2017, 3, p e1602051 (https://doi.org/10.1126/sciadv.1602051).

105. Liu, T.; Xu, J.-J.; Liu, Q.-C.; Chang, Z.-W.; Yin, Y.-B.; Yang, X.-Y.; Zhang, X.-B. Small, 2017, 13, p 1602952 (https://doi.org/10.1002/smll.201602952).

106. Garcia, S. O.; Ulyanova, Y. V.; Figueroa-Teran, R.; Bhatt, K. H.; Singhal, S.; Atanassov, P. ECS J. Solid State Sci. Technol., 2016, 5, pp M3075-M3081 (https://dx.doi.org/10.1149\%2F2.0131608jss).

107. Bandodkar, A. J.; Jeerapan, I.; You, J.-M.; Nuñez-Flores, R.; Wang, J. Nano Letters, 2016, 16, pp 721-727 (https://doi.org/10.1021/acs.nanolett.5b04549).

108. Ostfeld, A. E.; Arias, A. C., Flexible Printed Electron., 2017, 2, p 013001 (https://doi.org/10.1088/20588585/aa5750).

109. Zhu, J.; Tang, S.; Wu, J.; Shi, X.; Zhu, B.; Meng, X. Adv. Energy Mater., 2017, 7, p 1601234 (https:// doi.org/10.1002/aenm.201601234).

110. Yang, Y.; Huang, Q.; Niu, L.; Wang, D.; Yan, C.; She, Y.; Zheng, Z. Adv. Mater., 2017, 29, p 1606679 (https://doi.org/10.1002/adma.201606679).

111. Wu, G.; Tan, P.; Wu, X.; Peng, L.; Cheng, H.; Wang, C.-F.; Chen, W.; Yu, Z.; Chen, S. Adv. Funct. Mater., 2017, 27, p 1702493 (https://doi.org/10.1002/adfm.201702493).

112. Yang, Y.; Zhang, H.; Lin, Z.-H.; Zhou, Y. S.; Jing, Q.; Su, Y.; Yang, J.; Chen, J.; Hu, C.; Wang, Z. L. ACS Nano, 2013, 7, pp 9213-9222 (https://doi.org/10.1021/nn403838y).

113. Zheng, Q.; Shi, B.; Li, Z.; Wang, Z. L. Adv. Sci., 2017, 4, p 1700029 (https://doi.org/10.1002/ advs.201700029).

114. Park, D. Y.; Joe, D. J.; Kim, D. H.; Park, H.; Han, J. H.; Jeong, C. K.; Park, H.; Park, J. G.; Joung, B.; Lee, K. J. Adv. Mater., 2017, 29, p 1702308 (https://doi.org/10.1002/adma.201702308).

115. Wu, Z.; Wang, Y.; Liu, X.; Lv, C.; Li, Y.; Wei, D.; Liu, Z. Adv. Mater., 2019, 31, p 1800716 (https://doi. org/10.1002/adma.201800716).

116. Chen, X.; Huang, H.; Pan, L.; Liu, T.; Niederberger, M. Adv. Mater., 2019, 31, p 1904648 (https://doi. org/10.1002/adma.201904648).

117. Song, W.-J.; Kong, M.; Cho, S.; Lee, S.; Kwon, J.; Son, H. B.; Song, J. H.; Lee, D.-G.; Song, G.; Lee, S.-Y.; et al. Adv. Funct. Mater., 2020, 30, p 2003608 (https://doi.org/10.1002/adfm.202003608).

118. Zhang, N.; Dong, Y.; Wang, Y.; Wang, Y.; Li, J.; Xu, J.; Liu, Y.; Jiao, L.; Cheng, F. ACS Appl. Mater. Interfaces, 2019, 11, pp 32978-32986 (https://doi.org/10.1021/acsami.9b10399).

119. Qiu, Y.; Li, G.; Hou, Y.; Pan, Z.; Li, H.; Li, W.; Liu, M.; Ye, F.; Yang, X.; Zhang, Y. Chem. Mater., 2015, 27, pp 1194-1200 (https://doi.org/10.1021/cm503784x).

120. Pu, X.; Li, L.; Liu, M.; Jiang, C.; Du, C.; Zhao, Z.; Hu, W.; Wang, Z. L. Adv. Mater., 2016, 28, pp 98105 (https://doi.org/10.1002/adma.201504403).

121. Zheng, Y.; Yang, Y.; Chen, S.; Yuan, Q. Cryst. Eng. Comm., 2016, 18, pp 4218-4235 (https://doi. org/10.1039/C5CE02510A).

122. Moon, H.; Lee, H.; Kwon, J.; Suh, Y. D.; Kim, D. K.; Ha, I.; Yeo, J.; Hong, S.; Ko, S. H. Sci. Rep., 2017, 7, p 41981 (https://doi.org/10.1038/srep41981). 
123. Green, M. A.; Dunlop, E. D.; Levi, D. H.; Hohl-Ebinger, J.; Yoshita, M.; Ho-Baillie, A. W. Y. Photovoltaics, 2019, 27, pp 565-575 (https://doi.org/10.1002/pip.3171).

124. Mirchev, M.; Mircheva, I.; Kerekovska, A. J. Med. Internet Res., 2020, 22, p e22214 (https://doi. org/10.2196/22214).

125. Poon, C. C. Y.; Yuan-Ting, Z.; Shu-Di, B. IEEE Commun. Mag., 2006, 44, pp 73-81 (https://doi. org/10.1109/MCOM.2006.1632652).

126. Chen, F.; Deng, P.; Wan, J.; Zhang, D.; Vasilakos, A. V.; Rong, X. Int. J. Distrib. Sens. Netw., 2015, 11, p 431047 (https://doi.org/10.1155/2015/431047).

127. Wu, X.; Zhu, X.; Wu, G.; Ding, W. IEEE Trans. Knowl. Data Eng., 2014, 26, pp 97-107 (https://doi. org/10.1109/TKDE.2013.109).

128. Doukas, C.; Maglogiannis, I. Managing Wearable Sensor Data through Cloud Computing, 2011 IEEE Third International Conference on Cloud Computing Technology and Science, Athens, 2011, pp 440 445 (https://doi.org/10.1109/CloudCom.2011.65).

129. Mejía-Salazar, J. R.; Rodrigues Cruz, K.; Materón Vásques, E. M. Sensors, 2020, 20, p 1951 (https:// doi.org/10.3390/s20071951).

130. Yang, Y.; Gao, W. Chem. Soc. Rev., 2019, 48, pp 1465-1491 (https://doi.org/10.1039/C7CS00730B).

131. Choi, C.; Lee, Y.; Cho, K. W.; Koo, J. H.; Kim, D. H. Acc. Chem. Res., 2019, 52, pp 73-81 (https://doi. org/10.1021/acs.accounts.8b00491).

132. Woo, M. W.; Lee, J.; Park, K. Future Gener. Comput. Syst., 2018, 78, pp 626-640 (https://doi. org/10.1016/j.future.2017.04.004).

133. Christodouleas, D. C.; Kaur, B.; Chorti, P. ACS Cent. Sci., 2018, 4, pp 1600-1616 (https://doi. org/10.1021/acscentsci.8b00625).

134. Imani, S.; Bandodkar, A. J.; Mohan, A. M.; Kumar, R.; Yu, S.; Wang, J.; Mercier, P. P. Nat. Commun., 2016, 7, p 11650 (https://doi.org/10.1038/ncomms11650).

135. World Health Organization. Global Report on Diabetes; World Health Organization: Geneva, Switzerland, 2016 (https://www.who.int/publications/i/item/9789241565257).

136. Bruen, D.; Delaney, C.; Florea, L.; Diamond, D. Sensors, 2017, 17, p 1866 (https://doi.org/10.3390/ s17081866).

137. Vashist, S. K. Anal Chim Acta, 2012, 750, pp 16-27 (https://doi.org/10.1016/j.aca.2012.03.043).

138. Lee, H.; Choi, T. K.; Lee, Y. B.; Cho, H. R.; Ghaffari, R.; Wang, L.; Choi, H. J.; Chung, T. D.; Lu, N.; Hyeon, T.; et al. Nat. Nanotechnol., 2016, 11, pp 566-572 (https://doi.org/10.1038/nnano.2016.38).

139. Alizadeh, A.; Burns, A.; Lenigk, R.; Gettings, R.; Ashe, J.; Porter, A.; McCaul, M.; Barrett, R.; Diamond, D.; White, P.; et al. Lab on a Chip, 2018, 18, pp 2632-2641 (https://doi.org/10.1039/C8LC00510A).

140. Lu, Y.; Jiang, K.; Chen, D.; Shen, G. Nano Energy, 2019, 58, pp 624-632 (https://doi.org/10.1016/j. nanoen.2019.01.084).

141. De Boeck, K.; Vermeulen, F.; Dupont, L. Presse Med., 2017, 46, pp e97-e108 (https://doi.org/10.1016/j. Ipm.2017.04.010).

142. Nyein, H. Y. Y.; Tai, L.-C.; Ngo, Q. P.; Chao, M.; Zhang, G. B.; Gao, W.; Bariya, M.; Bullock, J.; Kim, H.; Fahad, H. M.; et al. ACS Sens., 2018, 3, pp 944-952 (https://doi.org/10.1021/acssensors.7b00961).

143. Kinnamon, D.; Ghanta, R.; Lin, K.-C.; Muthukumar, S.; Prasad, S. Sci. Rep., 2017, 7, p 13312 (https://doi.org/10.1038/s41598-017-13684-7).

144. Parlak, O.; Keene, S. T.; Marais, A.; Curto, V. F.; Salleo, A. Sci. Adv., 2018, 4, eaar2904 (https://doi. org/10.1126/sciadv.aar2904).

145. Anastasova, S.; Crewther, B.; Bembnowicz, P.; Curto, V.; Ip, H. M. D.; Rosa, B.; Yang, G.-Z. Biosens. Bioelectron., 2017, 93, pp 139-145 (https://doi.org/10.1016/j.bios.2016.09.038).

146. Arshad, R.; Rhouati, A.; Hayat, A.; Nawaz, M. H.; Yameen, M. A.; Mujahid, A.; Latif, U. Appl. Biochem. Biotechnol., 2020, 191, pp 1384-1394 (https://doi.org/10.1007/s12010-020-03285-y).

147. Zhao, C.; Liu, X. Biomicrofluidics, 2016, 10, p 024119 ( https://doi.org/10.1063/1.4945311).

148. Goud, K. Y.; Moonla, C.; Mishra, R. K.; Yu, C.; Narayan, R.; Litvan, I.; Wang, J. ACS Sens., 2019, 4, pp 2196-2204 (https://doi.org/10.1021/acssensors.9b01127). 
149. Mannoor, M. S.; Tao, H.; Clayton, J. D.; Sengupta, A.; Kaplan, D. L.; Naik, R. R.; Verma, N.; Omenetto, F. G.; McAlpine, M. C. Nat. Commun., 2012, 3, p 763 (https://doi.org/10.1038/ncomms1767).

150. Ramos, J.; Ausín, J.L.; Torelli, G.; Duque-Carrillo, J., IEEE, 2009, pp 49-52 (https://doi.org/10.1109/ PHEALTH.2009.5754839).

151. Coyle, S.; Morris, D.; Lau, K.-T.; Diamond, D.; Moyna, N. IEEE Computer Society, 2009, pp 307-311 (https://doi.org/10.1109/BSN.2009.57).

152. Huang, X.; Liu, Y.; Cheng, H.; Shin, W.-J.; Fan, J. A.; Liu, Z.; Lu, C.-J.; Kong, G.-W.; Chen, K.; Patnaik, D.; et al. Adv. Funct. Mater., 2014, 24, pp 3846-3854 (https://doi.org/10.1002/adfm.201303886).

153. Ciui, B.; Martin, A.; Mishra, R. K.; Nakagawa, T.; Dawkins, T. J.; Lyu, M.; Cristea, C.; Sandulescu, R.; Wang, J. ACS Sens., 2018, 3, pp 2375-2384 (https://doi.org/10.1021/acssensors.8b00778).

154. Kim, J.; Jeerapan, I.; Sempionatto, J. R.; Barfidokht, A.; Mishra, R. K.; Campbell, A. S.; Hubble, L. J.; Wang, J. Acc. Chem. Res, 2018, 51, pp 2820-2828 (https://doi.org/10.1021/acs.accounts.8b00451).

155. Coyle, S.; Curto, V. F.; Benito-Lopez, F.; Florea, L.; Diamond, D. - Wearable Bio and Chemical Sensors. In: Sazonov, E.; Neuman, M. R. (Eds.) Wearable Sensors. Academic Press, 2014, Chapter 2.1 (https://doi.org/10.1016/B978-0-12-418662-0.00002-7).

156. Kingery, A. F.; Allen, H. E. Toxicol. Environ. Chem., 1995, 47, pp 155-184 (https://doi. org/10.1080/02772249509358137).

157. Mishra, R. K.; Barfidokht, A.; Karajic, A.; Sempionatto, J. R.; Wang, J.; Wang, J. Sens. Actuators, B, 2018, 273, pp 966-972 (https://doi.org/10.1016/j.snb.2018.07.001).

158. Mishra, R. K.; Martín, A.; Nakagawa, T.; Barfidokht, A.; Lu, X.; Sempionatto, J. R.; Lyu, K. M.; Karajic, A.; Musameh, M. M.; Kyratzis, I. L.; et al. Biosens. Bioelectron., 2018, 101, pp 227-234 (https://doi. org/10.1016/j.bios.2017.10.044).

159. Campbell, A. S.; Kim, J.; Wang, J. Curr. Opin. Electrochem., 2018, 10, pp 126-135 (https://doi. org/10.1016/j.coelec.2018.05.014).

160. De Boni, R.; Bozzetti, M. C.; Hilgert, J.; Sousa, T.; Von Diemen, L.; Benzano, D.; Menegon, G.; Holmer, B.; Duarte, P. C. A. V.; Pechansky, F. Accid. Anal. Prev., 2011, 43, pp 1408-1413 (https://doi. org/10.1016/j.aap.2011.02.016).

161. Arakawa, T.; Kuroki, Y.; Nitta, H.; Chouhan, P.; Toma, K.; Sawada, S.-i.; Takeuchi, S.; Sekita, T.; Akiyoshi, K.; Minakuchi, S.; et al. Biosens. Bioelectron., 2016, 84, pp 106-111 (https://doi.org/10.1016/j. bios.2015.12.014).

162. Yao, H.; Liao, Y.; Lingley, A. R.; Afanasiev, A.; Lähdesmäki, I.; Otis, B. P.; Parviz, B. A. J. Micromech. Microeng., 2012, 22, p 075007 (https://doi.org/10.1088/0960-1317/22/7/075007).

163. Lee, Y.; Howe, C.; Mishra, S.; Lee, D. S.; Mahmood, M.; Piper, M.; Kim, Y.; Tieu, K.; Byun, H.-S.; Coffey, J. P.; et al. Proc. Natl. Acad. Sci. U. S. A., 2018, 115, pp 5377-5382 (https://doi.org/10.1073/ pnas.1719573115).

164. Thomas, N.; Lähdesmäki, I.; Parviz, B. A. Sens. Actuators, B, 2012, 162, pp 128-134 (https://doi. org/10.1016/j.snb.2011.12.049).

165. Yao, S.; Myers, A.; Malhotra, A.; Lin, F.; Bozkurt, A.; Muth, J. F.; Zhu, Y. Adv. Healthcare Mater., 2017, 6, p 1601159 (https://doi.org/10.1002/adhm.201601159).

166. Jiang, H.; Zhou, X.; Kulkarni, S.; Uranian, M.; Seenivasan, R.; Hall, D. A. IEEE, 2018, pp 1-4 (https:// doi.org/10.1109/CICC.2018.8357045).

167. Barfidokht, A.; Mishra, R. K.; Seenivasan, R.; Liu, S.; Hubble, L. J.; Wang, J.; Hall, D. A. Sens. Actuators, B, 2019, 296, p 126422 (https://doi.org/10.1016/j.snb.2019.04.053). 